\title{
๖Two Leading Modes of Wintertime Atmospheric Circulation Drive the Recent Warm Arctic-Cold Eurasia Temperature Pattern ${ }^{\mathscr{O}}$
}

\author{
KUNHUI YE \\ Alfred-Wegener-Institut Helmholtz-Zentrum für Polar- und Meeresforschung, Bremerhaven, Germany, and Department of Earth Sciences, \\ Uppsala University, Uppsala, Sweden \\ GABRIELE MESSORI \\ Department of Earth Sciences, Uppsala University, Uppsala, and Department of Meteorology and Bolin Centre for Climate Research, \\ Stockholm University, Stockholm, Sweden
}

(Manuscript received 31 May 2019, in final form 16 October 2019)

\begin{abstract}
The wintertime warm Arctic-cold Eurasia (WACE) temperature trend during 1990-2010 was characterized by accelerating warming in the Arctic region, cooling in Eurasia, and accelerating autumn/winter Arctic sea ice loss. We identify two atmospheric circulation modes over the North Atlantic-northern Eurasian sector that displayed strong upward trends over the same period and can explain a large part of the observed decadal WACE pattern. Both modes bear a close resemblance to well-known teleconnection patterns and are relatively independent from variability in Arctic sea ice cover. The first mode (PC1) captures the recent negative trends in the North Atlantic Oscillation and increased Greenland blocking frequency, while the second mode (PC2) is reminiscent of a Rossby wave train and reflects an increased blocking frequency over the Urals and north Asia. We find that the loss in the Arctic sea ice and the upward trends in PC1 and PC2 together account for most of the decadal Arctic warming trend $(>80 \%)$. However, the decadal Eurasian cooling trends may be primarily ascribed to the two circulation modes alone: all of the cooling in Siberia is contributed to by PC1 and $65 \%$ of the cooling in East Asia by their combination (the contribution by PC2 doubles that by PC1). Enhanced intraseasonal activity of the two circulation modes increases blocking frequencies over Greenland, the Ural region, and north Asia, which drive anomalous moisture/heat flux toward the Arctic and alter the downward longwave radiation. This also weakens warm advection and enhances advection of cold Arctic airmasses towards Eurasia.
\end{abstract}

\section{Introduction}

Surface air temperature (SAT) has been rising at a much higher rate in the Arctic than in other regions of the globe, a phenomenon referred to as Arctic amplification (AA; Serreze et al. 2009; Screen and Simmonds 2010; Cohen et al. 2014; Walsh 2014). Concurrently, the Arctic sea ice extent has been decreasing at rates that are unprecedented in both the satellite record and

Denotes content that is immediately available upon publication as open access.

Supplemental information related to this paper is available at the Journals Online website: https://doi.org/10.1175/JCLI-D-190403.s1.

Corresponding author: Kunhui Ye, kunhui.ye@geo.uu.se paleoreconstructions (Kinnard et al. 2011). Interestingly, midlatitude continents, and particularly Eurasia, have instead displayed cooling trends in SAT over recent decades (Cohen et al. 2014). A similar pattern was also observed during the early twentieth century (1920s-30s; Johannessen et al. 2004). This phenomenon, characterized by warming and cooling trends, respectively, in the Arctic region and the midlatitudes, is termed warm Arctic-cold continent (WACC; Overland et al. 2011; Cohen et al. 2014; Chen et al. 2018) or more specifically, warm Arctic-cold Eurasia (WACE; Mori et al. 2014).

The wintertime WACC/WACE in recent decades (1990-2010) has been accompanied by remarkable changes in the atmospheric circulation and occurrence of extreme weather events. Examples include the weakening of the meridional temperature gradient and zonal winds at midlatitudes (e.g., Francis and Vavrus 2015; Chen et al. 2018) and an increase in atmospheric 
blocking frequency over the Urals, Greenland, and Siberia (Luo et al. 2016a; Ye et al. 2018; Chen et al. 2018). Additionally, anticyclone activity and the frequency of cold extremes over Eurasia have both intensified in recent years (e.g., Zhang et al. 2008; Overland et al. 2011; Zhang et al. 2012; Cohen et al. 2010, 2014).

The WACC/WACE temperature pattern and the increased number of midlatitude wintertime cold extremes have drawn significant scientific attention. $\mathrm{Nu}-$ merous studies have linked recent cold midlatitude winters to the decline in Arctic sea ice (e.g., Honda et al. 2009; Petoukhov and Semenov 2010; Liu et al. 2012; Inoue et al. 2012; Cohen et al. 2014, and references therein). For Eurasia, the Barents and Kara Sea (BKS) region emerges as being of particular relevance in terms of both atmospheric circulation and sea ice cover anomalies (e.g., Honda et al. 2009; Petoukhov and Semenov 2010; Zhang et al. 2012; Inoue et al. 2012; Tang et al. 2013; Mori et al. 2014; Zhang et al. 2018). Increased Ural blocking frequency and persistence may play an important role in warming the BKS and cooling Eurasia (Luo et al. 2016a; Yao et al. 2017; B. Luo et al. 2017). This leads to a complex feedback loop, since increased atmospheric blocking frequency may be contributing to accelerating sea ice loss in the BKS (Gong and Luo 2017) yet is itself influenced by the sea ice loss in the region (Luo et al. 2016a). Mori et al. (2014) identified the WACE pattern as the second empirical orthogonal function (EOF) of SAT variability over the ArcticEurasian sector, excited directly by the sea ice decline over the BKS. Additional proposed mechanisms contributing to the WACE pattern include internal atmospheric variability (e.g., McCusker et al. 2016; Sun et al. 2016; Ogawa et al. 2018), the poleward shift of the oceanic front in the Gulf Stream region (Sato et al. 2014; Simmonds and Govekar 2014), anomalies in Eurasian snow cover (Xu et al. 2018) and manifestations of independent phenomena that jointly contribute to an anomalous temperature dipole (Ye et al. 2018). Others have analyzed the low-frequency variability in the WACE pattern. Sung et al. (2018), for example, have highlighted the existence of a strong interdecadal variability, associated with the modulation of Rossby waves by the mean-flow conditions in the North Atlantic sector, altered atmospheric baroclinicity over the Gulf Stream region, and changes in the Atlantic meridional overturning circulation.

The large variety of physical explanations proposed for the WACE pattern is part of the broader uncertainty concerning Arctic-midlatitudes linkages. A number of mechanisms for the impacts of AA and sea ice loss on the midlatitudes have been proposed, including the modulation of the storm tracks (e.g., Overland et al.
2011), of the eddy-driven jet stream (Francis and Vavrus 2015), of planetary waves (e.g., Petoukhov and Semenov 2010; Tang et al. 2013), and of the North Atlantic Oscillation/Arctic Oscillation (NAO/AO; e.g., Alexander et al. 2004; Screen et al. 2014). However, large uncertainties remain concerning the robustness and magnitude of these linkages (Cohen et al. 2014), with contrasting results in the literature (e.g., Barnes 2013; Barnes and Screen 2015; Perlwitz et al. 2015; Cattiaux et al. 2016; McCusker et al. 2016; Sigmond and Fyfe 2016; Sun et al. 2016). The sea ice loss in the Arctic has been considered in a recent study as an unimportant factor for the Eurasian cold winters (Blackport et al. 2019). This conclusion is based on examining the direction of oceanic heat flux and the interaction between sea ice and the overlying atmosphere. Another recent study by Luo et al. (2019) suggests that the influence of the Arctic sea ice loss and warming depends on the background state of the atmospheric potential vorticity. Such finding further underscores the complex processes involved in the Arctic-midlatitudes linkages.

Here, we seek to address this outstanding challenge by analyzing potential midlatitude and Arctic drivers of the WACE pattern, and quantifying their respective contributions. We specifically identify two modes of atmospheric variability over the North Atlantic-Eurasia region that had distinct influences on the WACE pattern during the period 1990-2010. The first mode is dominated by an NAO/AO-like pattern. The second mode is a zonal wavelike pattern reminiscent of a combination of Ural blocking and NAO pattern (Luo et al. 2016b; Zhong et al. 2018), although here we do not focus on the relationship between Ural blocking and the WACE pattern. Previous studies have found a close association between similar atmospheric circulation modes and the WACE pattern (e.g., Luo et al. 2016a; Yao et al. 2017). In our study, we build upon these results by specifically investigating the two modes' intraseasonal, interannual and decadal variability, and linking the shorter-term relationship between the two modes and the WACE pattern to the latter's decadal trends. We further provide a quantitative analysis of the contribution by the two modes to the WACE trend. The analysis highlights the physical processes underlying this interplay and separates the footprint of the modes from that of regional sea ice loss. The search for modes specifically relevant to the WACE pattern, as opposed to canonical modes such as the NAO or the AO, provides the flexibility to identify targeted variability patterns that may result from the interactions between previously known circulation features. Moreover, the seamless analysis of variability at multiple time scales provides novel insights into the origin of the WACE pattern. 
Section 2 describes the data and statistical methods. The two atmospheric circulation modes and their respective contributions to the WACE pattern are discussed in sections 3 and 4, respectively. Section 5 investigates the processes that mediate the impacts of the two circulation modes. Section 6 discusses the impacts of local sea ice loss on the WACE pattern. Finally, section 7 provides a discussion and summary of the major findings.

\section{Data and methodology}

\section{a. Datasets and atmospheric circulation indices}

Atmospheric fields for 1980-2017 are taken from the European Centre for Medium-Range Weather Forecasts (ECMWF) ERA-Interim dataset (Dee et al. 2011). We use both daily and monthly mean fields of several dynamic and thermodynamic quantities. The daily fields are obtained by averaging 6-hourly values. Winter of a specific year includes December of the preceding year through to February of the year itself (DJF). We define the recent WACE pattern as the trend of the SAT over the Arctic and northern Eurasia during 1990-2010. The choice of temporal range follows Chen et al. (2018) and readers are referred to Cohen et al. (2014) for a comprehensive review of the WACE phenomenon.

We integrate the ERA-Interim fields with a variety of other data sources: the monthly mean geopotential height at $500 \mathrm{hPa}(\mathrm{Z} 500)$ from the National Aeronautics and Space Administration's MERRA-2 reanalysis (Gelaro et al. 2017); the Climatic Research Unit's (CRU) highresolution SAT data (CRU TS v. 4.01; Harris et al. 2014); and monthly sea surface temperature (SST) and sea ice concentration (SIC) from the Hadley Centre Sea Ice and Sea Surface Temperature dataset (Rayner et al. 2003). Daily sea ice fraction is instead taken from ERA-Interim; to avoid confusion, we also refer to this as SIC in our analysis.

The monthly indices of AO/NAO, east Atlantic pattern (EA), Polar/Eurasia pattern (POL), east Atlantic/ west Russia Pattern (EA/WR), Pacific-North American teleconnection (PNA), Scandinavia pattern (SCAND), and Niño-3.4, as well as the daily NAO index, are provided by the Climate Prediction Center of the National Oceanic and Atmospheric Administration (NOAA). The Siberian high $(\mathrm{SH})$ intensity index is defined as the cosine latitude-weighted area-mean SLP over $40^{\circ}-60^{\circ} \mathrm{N}, 80^{\circ}-$ $120^{\circ} \mathrm{E}$ [the same domain as in $\mathrm{Wu}$ and Wang (2002)].

Extreme cold days (T10p) are the days in each winter below the 10th percentile of the daily ERA-Interim SAT distribution over all the winters during 1980-2017 at every grid point. Daily wave activity flux (WAF) at $250 \mathrm{hPa}$ is computed following Takaya and Nakamura (2001). The atmospheric blocking frequency is calculated following Lejenäs and Økland (1983) and Tibaldi and Molteni (1990). To remove trends in the data, the time series are first smoothed with a 5-yr running average. The new time series is then subtracted from the original series, and the least squares linear method is used to remove the linear trend. Trends are estimated using the Theil-Sen trend estimate, and their significance is assessed by the Mann-Kendall nonparametric test for monotonic trends [see Mondal et al. (2012) for detailed descriptions of both methods]. To remove highfrequency fluctuations, time series and temporal fields are also smoothed with a 5-yr running average before computing their trends. The detrended fields/time series of the variables of interest exhibit moderate negative or near-zero one-year-lag autocorrelations. This suggests that serial correlation does not have to be accounted for when computing the trends in the raw fields/time series. However, since the smoothed fields/time series exhibit relatively large one-year-lag autocorrelations, significance of the trends of these smoothed fields/time series is assessed using the raw fields/time series. Finally, the significance of regressions and composite anomalies is evaluated using the Student's $t$ test.

\section{b. Defining two wintertime atmospheric circulation modes}

The first two leading modes of atmospheric wintertime variability are identified by applying an EOF analysis to the Z500 field over $20^{\circ}-90^{\circ} \mathrm{N}, 90^{\circ} \mathrm{W}-160^{\circ} \mathrm{E}$ (Figs. 1a,c). This domain covers most of the Arctic, North Atlantic, and Eurasia, and emphasizes the atmospheric circulation structures over the region of interest for the WACE pattern. Similar results are obtained when the domain for the EOF analysis is extended westward to $120^{\circ} \mathrm{W}$ and southward to $10^{\circ} \mathrm{S}$ (Fig. S1 in the online supplemental material). The two leading modes explain respectively $30 \%$ and roughly $18 \%$ of the total variance and are well separated according to the North et al. (1982) test. Similar spatial patterns are obtained when using the Z500 field from the MERRA-2 reanalysis (Fig. S2). Throughout the paper, the seasonal principal components of the two modes are referred to as $\mathrm{Z} 500-\mathrm{PC} 1 / \mathrm{PC} 2$; references to the polarity/sign of the modes correspond to the spatial loadings shown in Figs. 1a and 1c. The EOF approach we adopt, while widely used in describing atmospheric variability, facilitates an objective depiction of the temporal evolution of the two atmospheric circulation modes and thus allows for an easier assessment of their impacts on the recent WACE pattern.

To study the intraseasonal variability of the two modes, we first construct their daily standardized indices (Z500-D1/D2, respectively) by projecting the daily Z500 anomaly field onto the respective DJF Z500 anomaly 


\section{DJF Z500 EOFs 1980-2017}

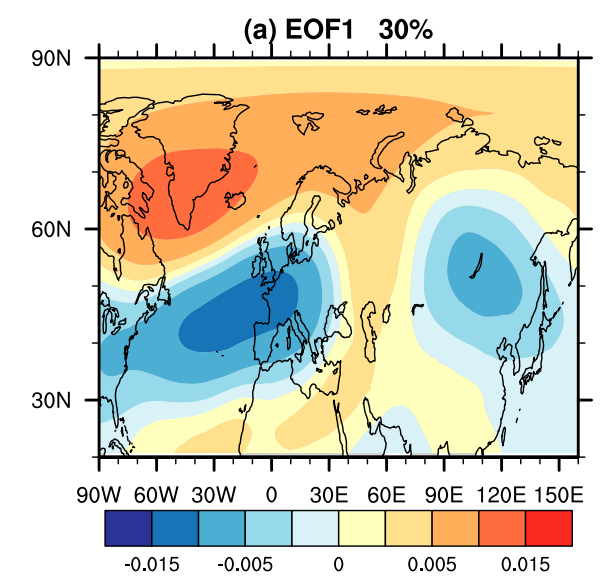

(c) EOF2 $18.3 \%$

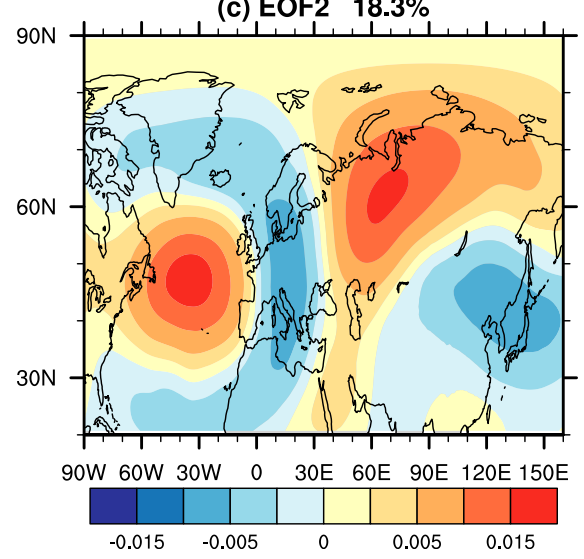

(b) Standardized PC1

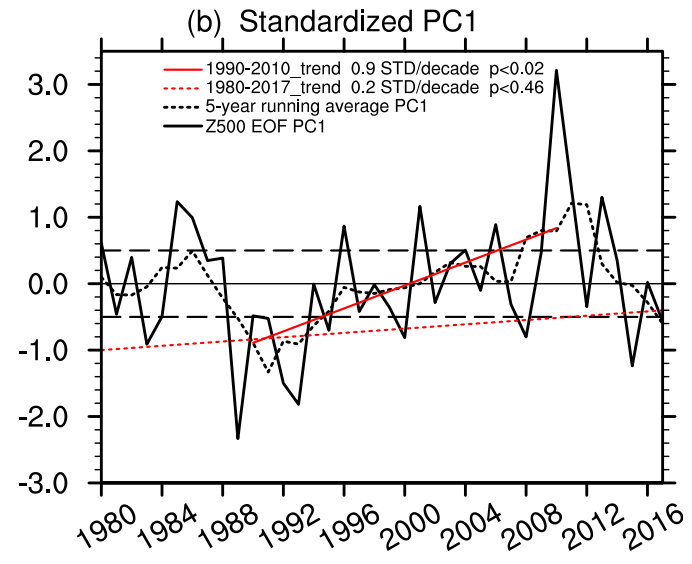

(d) Standardized PC2

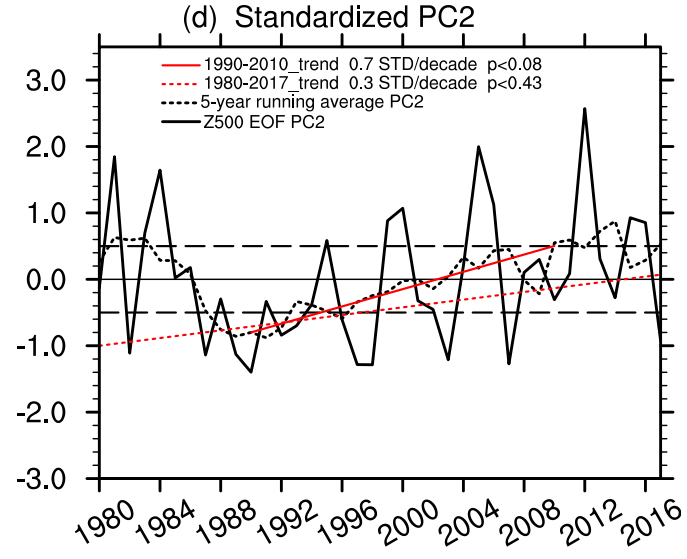

FIG. 1. The (a),(b) first and (c),(d) second EOF modes of winter geopotential height at $500 \mathrm{hPa}$ (Z500) during 1980-2017. The principal components (PCs; Z500-PC1/PC2) in the right panels are normalized with respect to their own standard deviations $\sigma$. Solid (dashed) red curves denote linear trends $\left(\sigma\right.$ decade $\left.^{-1}\right)$ during 1990-2010 (19802017) based on Theil-Sen trend estimate. Trend significance is assessed based on the Mann-Kendall nonparametric test for monotonic trends (see text). The dashed black curves denote 5-yr running averages. Horizontal dashed lines indicate $\pm 0.5 \sigma$.

patterns for years with high versus low PC values (section 3a). and normalizing by their standard deviation. We then define positive events of each atmospheric circulation mode. An event occurs when same-sign values of Z500-D1/D2 persist for at least 7 and at most 21 consecutive days, and the maximum/minimum value during this time is above a specific threshold. The 7-day persistence requirement ensures the detection of persistent events and is partly based on visual inspection. The 21-day upper limit is intended to separate different events, which may occur consecutively. Inspection of the evolution of the Z500-D1/D2 indices during the identified events indicates that the maximum index values can be viewed as the peaks of the events (Fig. S3). Reasonable changes in these requirements do not qualitatively alter our results. The threshold value to define positive events is set at $11.5 \sigma$. Events are merged if their maximum values occur less than seven days apart. An event is discarded if the maximum Z500-D1/D2 value occurs closer to the first day or last day of the event than one-fourth of the event duration. This excludes those events that have an unusually rapid development or decay during their life cycles and are not representative of the typical temporal evolution of the two modes.

To investigate the contribution of the circulation modes to SAT trends, we adopt a procedure conceptually similar to that of Iles and Hegerl (2017). First, both the SAT and the Z500-PC1/PC2 are detrended to minimize the impact of preexisting trends in the time series on the results. Next, regression coefficients of the SAT time series against Z500-PC1/PC2 are obtained, and linear trends in the original SAT time series and Z500PC1/PC2 during 1990-2010 are estimated. Finally, it is assumed that the relationship between the time series in 
TABLE 1. Correlation coefficients between EOF PCs of the DJF Z500 field and climate indices. Correlation coefficients significant at the $5 \%(1 \%)$ level are in italic (italic and bold). All fields are detrended according to the method described in the text.

\begin{tabular}{lcc}
\hline \hline & \multicolumn{2}{c}{ EOF PCs } \\
\cline { 2 - 3 } Index & DJF Z500-PC1 & DJF Z500-PC2 \\
\hline AO & $-\mathbf{0 . 9 3}$ & 0.28 \\
NAO & $-\mathbf{0 . 8}$ & $\mathbf{0 . 6 7}$ \\
EA & 0.43 & $-\mathbf{0 . 6}$ \\
PNA & 0.08 & 0.19 \\
EA/WR & -0.21 & $-\mathbf{0 . 5 5}$ \\
SCAND & $\mathbf{0 . 6 8}$ & -0.16 \\
POL & $-\mathbf{0 . 5}$ & -0.07 \\
Niño-3.4 & 0.19 & -0.18 \\
SH & -0.11 & $\mathbf{0 . 7 4}$ \\
\hline
\end{tabular}

terms of covariability at shorter time scales also holds for longer time scales. The contribution by Z500-PC1/ PC2 to the SAT trends is thus estimated by multiplying the trends of Z500-PC1/PC2 during 1990-2010 with the regression coefficients. This method is also used to estimate the contribution of the sea ice to the SAT trends.

\section{Two distinct wintertime atmospheric circulation modes}

\section{a. Description of the modes}

The first atmospheric mode resembles the AO/NAO (Fig. 1a), as well as the "Z500 extremes" pattern in Johnson et al. (2018). The corresponding PC (Z500-PC1, Fig. 1b) correlates strongly with the AO/NAO indices $(r=-0.93 /-0.8)$ and the SCAND pattern $(r=0.68$, Table 1). However, the partial correlation with the SCAND pattern adjusted for the AO/NAO dependence is significantly smaller $(r<0.2)$, suggesting that the relationship of Z500-PC1 with SCAND primarily mirrors that with the AO/NAO. The first circulation mode also exhibits a weak relationship with ENSO (Table 1) and a strong correlation with atmospheric blocking frequency over eastern Canada-Greenland (red lines; Fig. 2c).

The second circulation mode is characterized by a zonal wavelike pattern (Fig. 1c), reminiscent of the one in Zhong et al. (2018), albeit based on monthly composite anomalies in their study. The corresponding PC (Z500-PC2, Fig. 1d) exhibits moderate correlations with the EA/WR pattern $(r=-0.55)$ and NAO $(r=0.67)$, and a higher correlation with the SH $(r=0.74)$. The correlation with ENSO is again weak (Table 1), while a strong link emerges with blocking frequency across northern Eurasia (blue line; Fig. 2c).

Both the Z500-PC1 and Z500-PC2 display strong interannual variability and decadal trends. The strongest upward trends coincide with the timing of the recent WACE pattern during $1990-2010\left(0.9 \sigma\right.$ decade $^{-1}$ for Z500- (a) DJF blocking frequency climatology/trends

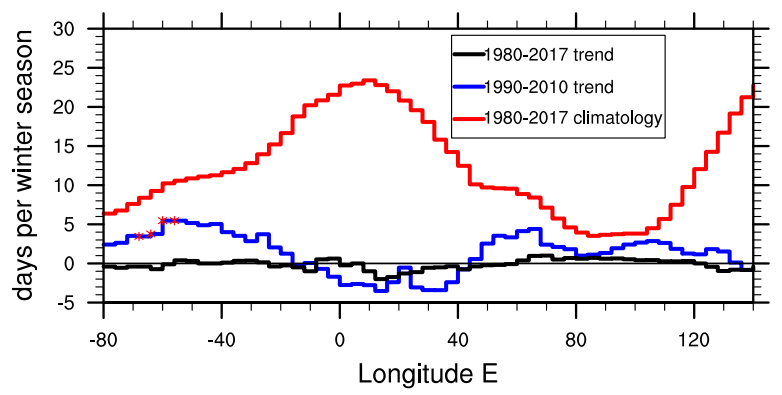

(b) DJF blocking frequency composites

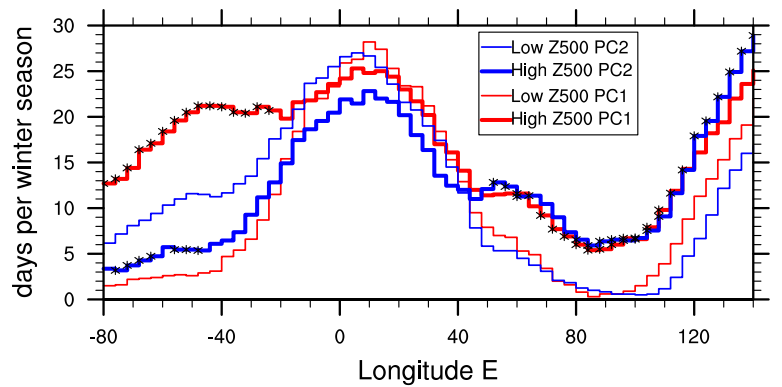

(c) Corr DJF Z500_PCs vs. DJF blocking frequency

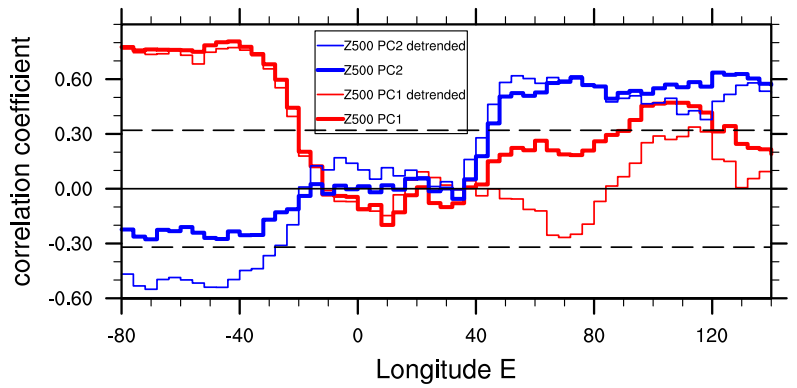

FIG. 2. (a) Climatology (1980-2017; red curve) and trend (days per winter season decade ${ }^{-1}$ ) of the longitudinal sector atmospheric blocking frequency during the period 1980-2017 (black curve) and 1990-2010 (blue curve). Red asterisks indicate that the trends are significant at the $10 \%$ level. (b) Composite longitudinal sector atmospheric blocking frequency for years above $+0.5 \sigma$ (thick lines) and below $-0.5 \sigma$ (thin lines) of Z500-PC1/PC2 (red and blue lines, respectively). Asterisks indicate that the composite frequencies are significantly different at the $5 \%$ level between the two groups of years. Units are days per winter season. (c) Correlation coefficients of the longitudinal sector atmospheric blocking frequency with the Z500-PC1/PC2 (red and blue lines, respectively). The dashed lines denote significance at the $5 \%$ level.

PC1, continuous red line in Fig. $1 \mathrm{~b}$ and $0.7 \sigma$ decade $^{-1}$ for Z500-PC2, continuous red line in Fig. 1d; see also section 2a here and Fig. 2 in Cohen et al. 2014). This immediately points to a possible connection between the three. The strong upward trend in Z500-PC1 is consistent with the concomitant negative trend in the NAO (Iles and Hegerl 2017). The trends in both PCs during the entire 1980-2017 period are much weaker $\left(0.2 \sigma\right.$ decade $^{-1}$ for Z500-PC1, dashed red line in Fig. 1b, and $0.3 \sigma$ decade $^{-1}$ for Z500-PC2, dashed red line in Fig. 1d). This is also true for the 


\section{Composites wrt. EOF PC1/PC2 DJF_Z500}

(a) Z500 wrt. EOF PC1

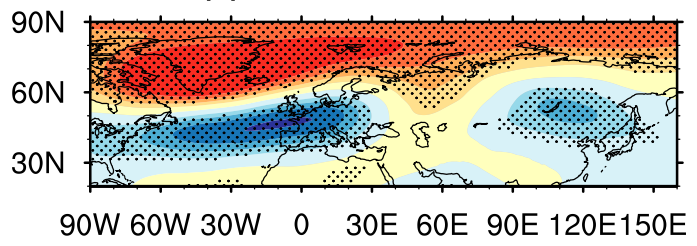

(b) Z500 wrt. EOF PC2

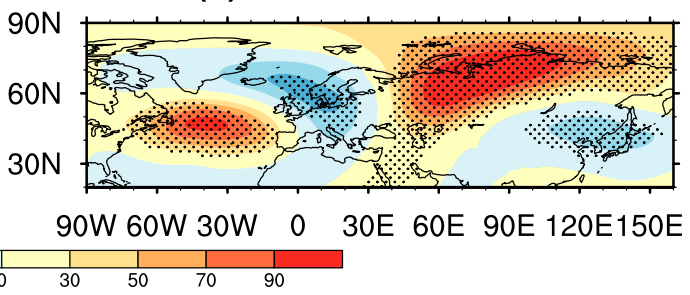

(c) UV300 wrt. EOF PC1

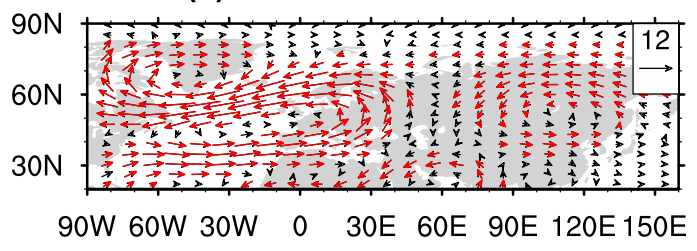

(d) UV300 wrt. EOF PC2

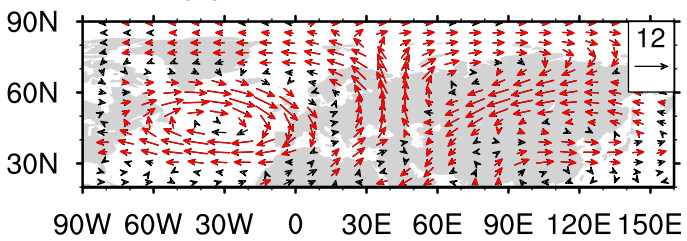

(e) SLP wrt. EOF PC1

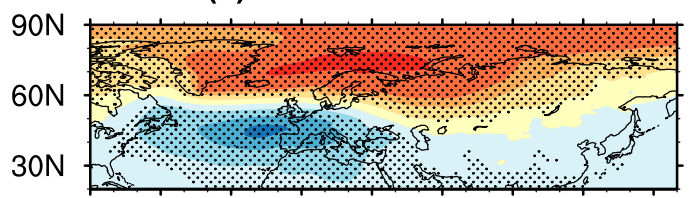

90W 60W 30W O 30E 60E 90E 120E150E

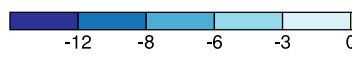

\section{CoW}




\section{Reg SAT/T10p vs. DJF Z500 PCs}

(a) SAT vs. PC1

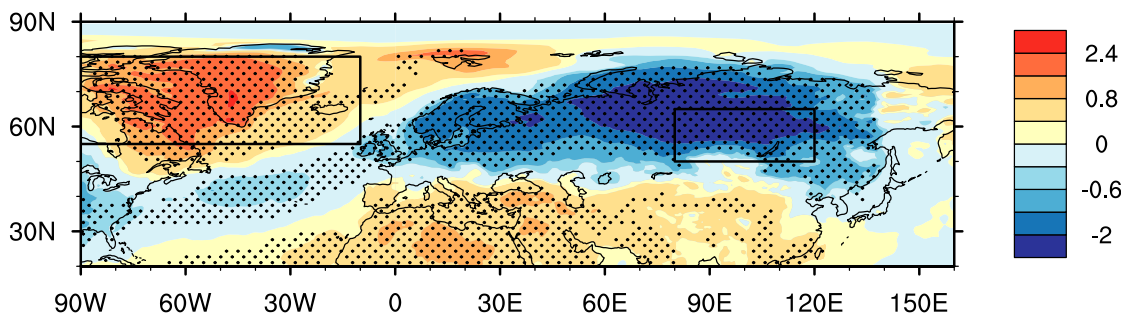

(b) T10p vs. PC1

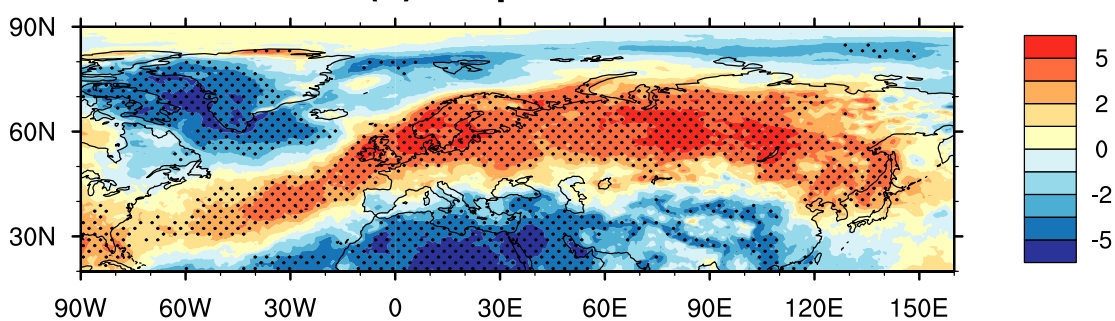

(c) SAT vs. PC2

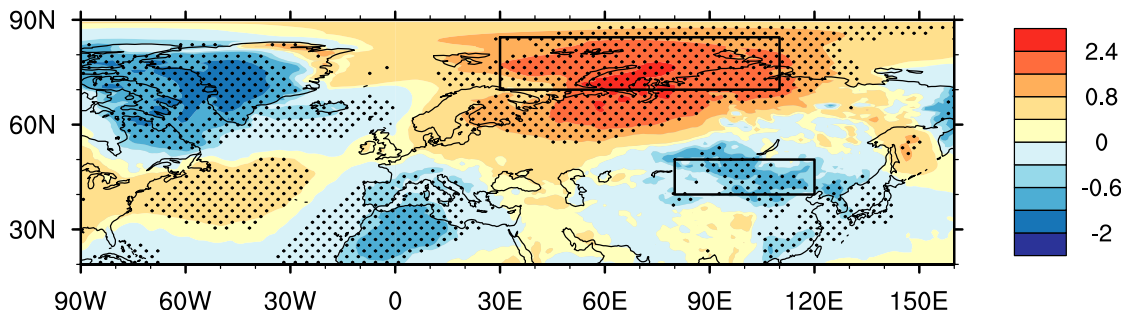

(d) T10p vs. PC2

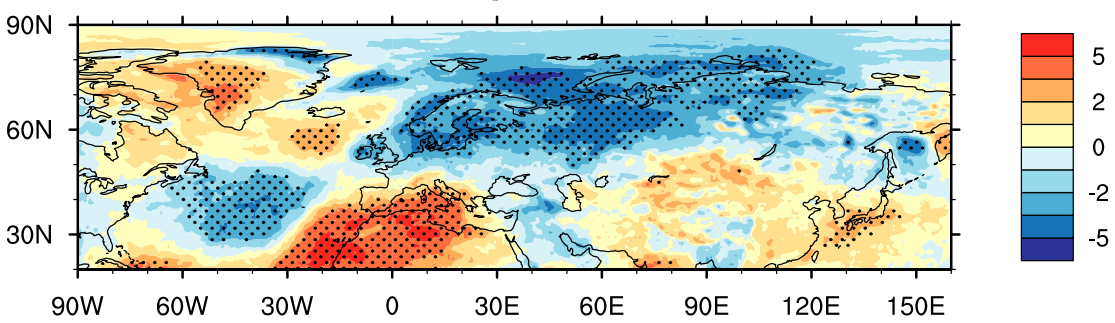

FIG. 4. Regression of (a),(c) surface air temperature (SAT; $\left.{ }^{\circ} \mathrm{C}\right)$ and (b),(d) cold extremes frequency (T10p; days per winter season) against Z500-PC1 in (a) and (b) and Z500-PC2 in (c) and (d) with trends removed before the computation. See text for the description of T10p. Stippling indicates significance at the $5 \%$ level. See text for details of the boxes in (a) and (c).

over northern Eurasia (thick blue line, Fig. 2b). The placement of the anticyclone and the blocking anomalies suggests that Ural blocking activity is an essential part of the zonal wavelike Z500 pattern, as also discussed in previous studies (e.g., Luo et al. 2016b). In contrast to the first mode, the positive phase of the second mode corresponds to a northeastward shift of the North Atlantic jet (not shown).

Overall, the two circulation modes therefore correspond to very different large-scale circulation patterns, preferred moisture pathways, and atmospheric blocking activity, underlying their distinct contributions to the WACE temperature pattern.

\section{Impacts of the two atmospheric circulation modes on interannual and decadal Arctic-Eurasian wintertime temperatures}

\section{a. Interannual temperature variability}

To reveal the impacts of the two modes of wintertime atmospheric circulation on the interannual variability of 
SAT trends / DJF Z500 PCs contribution

(a) SAT trend 1990-2010

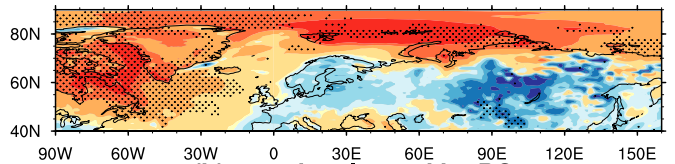

(b) trend estimated by PC1

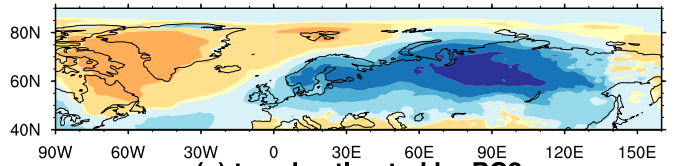

(c) trend estimated by PC2

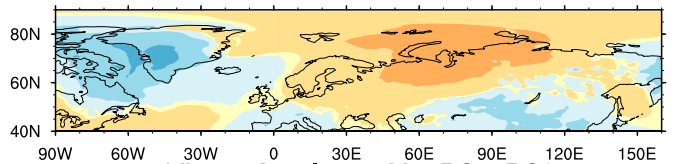

(d) trend estimated by PC1+PC2

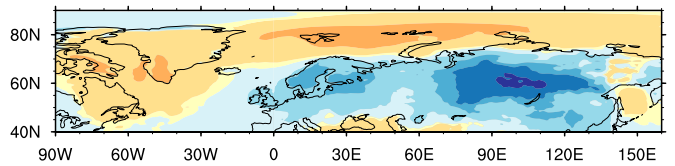

FIG. 5. (a) Linear trend of winter SAT $\left(\mathrm{K} \mathrm{decade}^{-1}\right)$ in ERAInterim data using the Theil-Sen trend estimate. Linear trend of winter SAT (K decade ${ }^{-1}$ ) as contributed to by (b) Z500-PC1, (c) Z500-PC2, and (d) their sum. See text for details about the estimation of trend contribution. Stippling indicates significance at the $5 \%$ level.

the SAT, all the fields are detrended before the analysis (section 2a). The SAT anomalies associated with Z500PC1 are characterized by a tripole (Fig. 4a), resembling the footprint of the negative NAO/AO (e.g., Hurrell 1996; He et al. 2017; Iles and Hegerl 2017). The frequency of cold temperature extremes over a large swath of northern Eurasia is very sensitive to the mode (Fig. 4b).

The SAT anomaly pattern associated with Z500-PC2 is very different and reflects the mode's wavelike structure (Fig. 4c). The strong warming over BKS and its surrounding areas stands in stark contrast to the strong cooling over East Asia. Significant decreases in the frequency of cold temperature extremes is observed in high-latitude Russia during the positive phase of the mode, while increases occur over Greenland, south of Iceland, and in the southern portion of the analysis domain (Fig. 4d).

\section{b. The warm Arctic-cold Eurasia decadal temperature pattern}

The SAT patterns associated with the two circulation modes exhibit strong temperature anomalies over the Arctic-Eurasian sector, albeit with differences in the exact locations of the largest regression values. To better understand the contributions of the two modes to the WACE pattern, the standardized area-mean SAT and T10p are computed for eastern Canada-Greenland $\left(10^{\circ}-90^{\circ} \mathrm{W}, 55^{\circ}-80^{\circ} \mathrm{N}\right)$, BKS $\left(30^{\circ}-110^{\circ} \mathrm{E}, 70^{\circ}-85^{\circ} \mathrm{N}\right)$,
Siberia $\left(80^{\circ}-120^{\circ} \mathrm{E}, 50^{\circ}-65^{\circ} \mathrm{N}\right)$, and East Asia $\left(80^{\circ}-120^{\circ} \mathrm{E}\right.$, $40^{\circ}-50^{\circ} \mathrm{N}$ ) (boxes in Figs. 4a,c). The domains are selected to match areas with large decadal trends (Fig. 5a). The separation of Siberia and East Asia is necessary as the two modes have distinct impacts on the temperatures in these two regions (Fig. 4).

The standardized time series of area-mean SAT/T10p over the four regional domains are depicted in Fig. 6a. The SATs over eastern Canada-Greenland (solid red curve) and BKS (dashed red curve) exhibit strong upward trends during the period 1990-2010. In sharp contrast to this, the time series of the SAT in Siberia (solid blue curve) and East Asia (dashed blue curve) are characterized by downward trends during the same period. These contrasting SAT trends are characteristic of the recent WACE temperature pattern. Both the warming and cooling trends are much smaller for the entire period (1980-2017, see Table 2). The cooling trends become particularly weak, suggesting that the 1990-2010 WACE period in Eurasia is not representative of the temperature trends over 1980-2017. During the WACE period, the time series of T10p in Siberia (solid green curve) and East Asia (dashed green curve) also feature upward trends.

We next estimate the fractional contribution of the two modes of wintertime atmospheric circulation to trends in the SAT during the recent WACE period, following the procedure outlined in section $2 \mathrm{~b}$. We find that over $40 \%$ of the SAT trends over eastern CanadaGreenland and BKS during 1990-2010 are explained by Z500-PC1 (44.9\%) and Z500-PC2 (41.6\%), respectively. The two atmospheric circulation modes thus account for a substantial fraction of the Arctic surface warming trend. The recent cooling trend in Siberia is predominantly due to the first circulation mode. The explained cooling trend is actually stronger than the observed one, indicating that other processes, including the second circulation mode, must have partly offset the effect of the first circulation mode. Over East Asia, the explained percentages during the same period are roughly $20.3 \%$ and $44.9 \%$ for the first and second modes, respectively. Some of these features reflect the negative NAO trend during 1989-2013, that led to large cooling trends in northern Eurasia (Iles and Hegerl 2017). However, the cooling trend over East Asia is more strongly tied to the second circulation mode rather than to the NAO-like first circulation mode (see also the regressions in Fig. 4a,c). The two atmospheric circulation modes are independent by construction, and together they therefore explain essentially the whole recent winter cooling trend over Siberia and a very large part of that over East Asia.

In terms of cold temperature extremes, the upward trend in T10p in Siberia is largely linked to the first 


\section{(a) Area-mean DJF SAT/T10p}

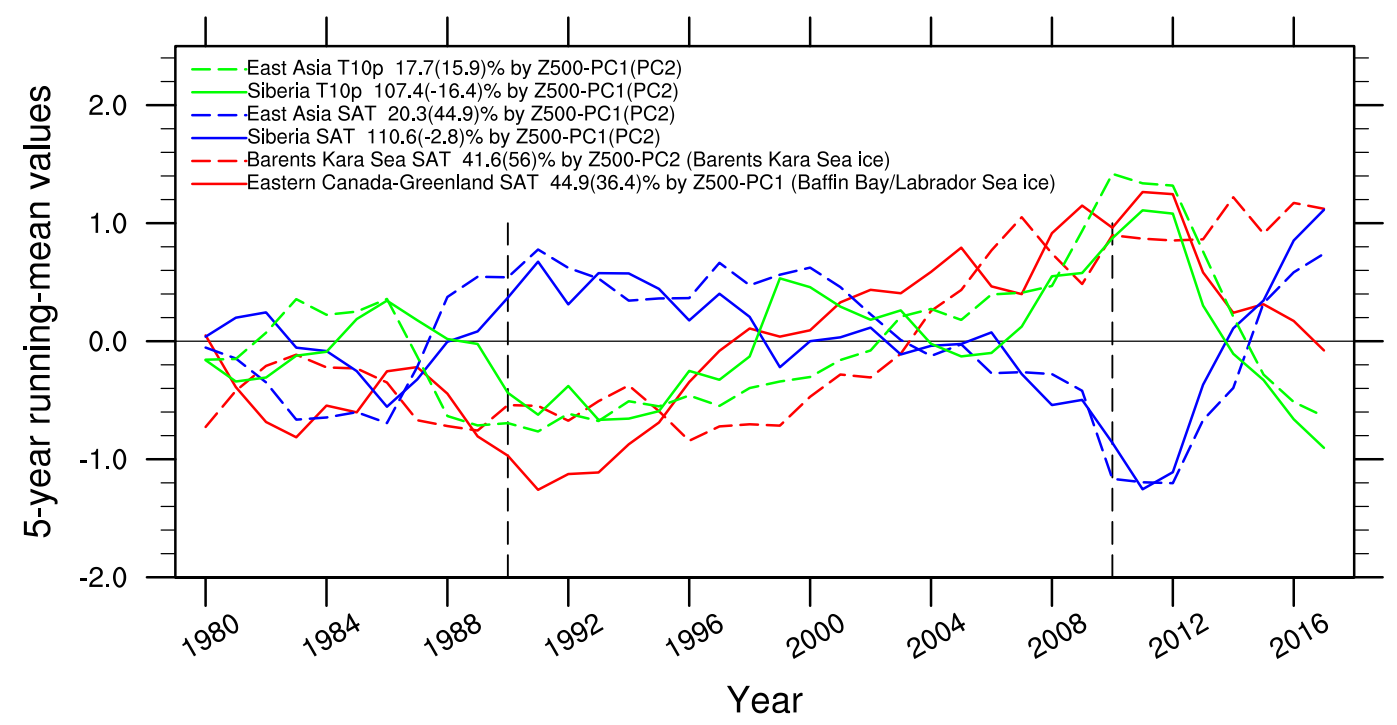

(b) Area-mean ON/DJF Sea ice

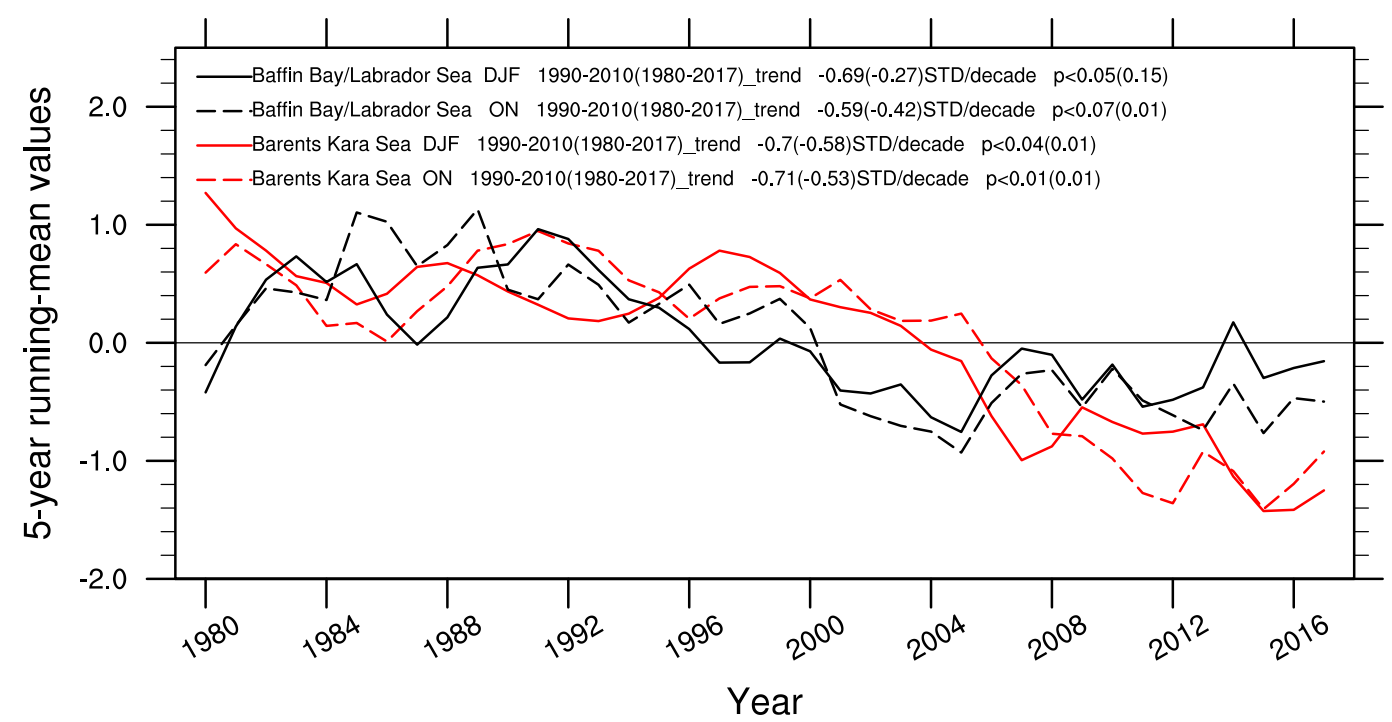

FIG. 6. (a) Area-mean time series of SAT for Barents-Kara Seas (BKS; dashed red), eastern Canada-Greenland (solid red), Siberia (solid blue), and East Asia (dashed blue). The solid (dashed) green line denotes the area-mean time series of T10p for Siberia (East Asia). (b) Area-mean time series of sea ice cover for BKS (solid red for DJF; dashed red for ON) and Baffin Bay/Labrador Sea (solid black for DJF; dashed black for ON). Time series are normalized with respect to their own standard deviations and smoothed with a 5-yr running average. Trend units for the sea ice are $\sigma$ decade $^{-1}$. Vertical dashed lines in (a) denote the years of 1990 and 2010, respectively. See text for details about the estimates of explained percentage of trends in SAT by Z500-PC1/PC2 and sea ice during 19902010 , indicated in the legends. ON $=$ October and November; DJF $=$ December-February.

circulation mode (see also Fig. 4b), which, as for the winter cooling trend in the same region, overestimates the observed changes. An atmospheric circulation pattern similar to this mode has indeed been associated with increased cold extremes over the land areas in the Northern Hemisphere during the recent socalled warming hiatus (Johnson et al. 2018). The link between the two modes and the increase in East Asian
T10p frequency is less evident. Both atmospheric circulation modes provide small contributions $(<20 \%)$ to the T10p trend in this region, and the contribution of the second circulation mode to the winter cooling trend is much stronger than its contribution to the upward trend in cold temperature frequency. Such a difference suggests that the processes leading to the mean winter temperature trend are likely different 
TABLE 2. Linear trends of the winter-mean SAT $\left(\sigma\right.$ decade $\left.^{-1}\right)$ for the period 1980-2017 over various regions as estimated from ERAInterim data and reconstructed from the regression method as described in the text. Values in parentheses denote trends computed for the period 1990-2010. ERA-Interim trends significant at the 10\% (1\%) level are in italic (italic and bold). BKS = Barents Kara Sea; ON = October and November; DJF $=$ December-February.

\begin{tabular}{lcccc}
\hline \hline & \multicolumn{3}{c}{ Regional SAT } \\
\cline { 2 - 5 } \multicolumn{1}{c}{ Sources for trends } & Eastern Canada-Greenland & BKS DJF & Siberia DJF & East Asia \\
SJF & SAT & $\mathbf{0 . 5}(0.9)$ & $-0.08(-0.6)$ & $-0.08(-0.6)$ \\
\hline ERA-Interim & $\mathbf{0 . 5 ( 1 . 2 )}$ & -0.04 & -0.12 & -0.02 \\
DJF Z500-PC1 & 0.1 & 0.17 & 0.01 & -0.12 \\
DJF Z500-PC2 & -0.12 & 0.04 & -0.34 & -0.15 \\
BKS ON Sea ice & 0.2 & 0.43 & -0.21 & -0.26 \\
BKS DJF Sea ice & -0.08 & -0.34 & 0.08 & 0.04 \\
Baffin Bay/Labrador Sea ON Sea ice & 0.15 & -0.21 & 0.0 & 0.07 \\
Baffin Bay/Labrador Sea DJF Sea ice & 0.19 & & & \\
\hline
\end{tabular}

from those leading to the increased cold extremes frequency in East Asia.

A procedure similar to the one adopted for the trend contributions can be used to construct the spatial trend patterns associated with the two DJF Z500 modes. The observed spatial SAT trend during 1990-2010 is characterized by strong warming in eastern CanadaGreenland and the BKS area, and cooling across northern Eurasia, and particularly Siberia-East Asia (Fig. 5a; as found in many previous studies, e.g., Cohen et al. 2014; Chen et al. 2018). The spatial patterns of SAT trend associated with Z500-PC1 and Z500-PC2 do not individually resemble the WACE pattern (cf. Fig. 5a with Figs. 5b,c). Z500-PC1 misses the strong warming over the BKS and the surrounding land areas (Fig. 5b). In fact, the AO/NAO trend during the WACE period cannot explain the warming in the Arctic (He et al. 2017). The strongest cooling trend is also shifted northward. Z500-PC2, on the other hand, misses the strong warming in eastern Canada-Greenland and the cooling across Europe and Siberia (Fig. 5c). However, the linear sum of the two spatial temperature trends (Fig. 5d) closely matches the reanalysis-based WACE pattern (Fig. 5a). The primary difference is a weaker warming over the Arctic. There are multiple plausible reasons for this discrepancy. The combination of the two atmospheric circulation modes accounts for only half of the total variance of the atmospheric circulation over the Arctic-Eurasian sector. Other wintertime drivers may thus contribute to the Arctic surface warming. Local sea ice loss is an obvious candidate for an additional warming mechanism (section 6). Since wintertime sea ice is only weakly correlated with the two atmospheric circulation modes (Table 3, see also section 6), it may drive a relatively independent contribution to the warming trend in the Arctic.

The warming trends in eastern Canada-Greenland and BKS during the 1990-2010 WACE period are roughly double those during the whole 1980-2017 period (Table 2). The cooling trends in Siberia and East Asia during the WACE period are about 8 times larger than those during the whole period considered here. Moreover, all of the latter trends are near zero. We thus suggest that the warming trend in the Arctic during the WACE period represents an accelerated decadal warming embedded in a long-term warming trend. In contrast, the cooling trend over Eurasia during the WACE period emerges as a strong decadal anomaly with a lower statistical significance, which has partly reversed after 2010 (Fig. 6a). This matches the weakening or even reversal of the decadal upward trend in both atmospheric circulation modes after 2010 (Figs. 1b,d), further supporting their close link to the WACE pattern.

\section{Physical interpretation of the WACE pattern and intraseasonal variability of the two atmospheric circulation modes}

\section{a. Intraseasonal versus longer-term variability in the modes}

The two leading atmospheric circulation modes discussed above provide a strong contribution to the recent WACE temperature pattern. We elucidate this contribution by analyzing how these two circulation modes drive the surface temperature anomaly patterns on intraseasonal scales. The winter-mean Z500-D1/D2 values exhibit similar temporal evolutions to the Z500PC1/PC2 (cf. Figs. 1b,d and 7). The correlation coefficient between the two is 0.97 (0.86) for the first (second) mode. This suggests that the long-term signature of the two modes results from recurring features on intraseasonal time scales. As for the PCs, the trend of the winter-mean Z500-D1/D2 during the recent WACE period (i.e., 1990-2010) is significantly larger than that during the whole period (i.e., 1980-2017). This suggests 
TABLE 3. Correlation coefficients between area-mean sea ice and Z500-PC1/PC2, SAT, and T10p over various regions. Correlation coefficients significant at the $5 \%(1 \%)$ level are in italic (italic and bold). All fields are detrended according to the method as described in the text. BKS = Barents Kara Sea; ON = October and November; DJF = December, January and February.

\begin{tabular}{|c|c|c|c|c|c|c|c|c|}
\hline Area-mean sea ice & $\begin{array}{c}\text { DJF } \\
\text { Z500-PC1 }\end{array}$ & $\begin{array}{c}\mathrm{DJF} \\
\mathrm{Z} 500-\mathrm{PC} 2\end{array}$ & $\begin{array}{l}\text { BKS DJF } \\
\text { SAT }\end{array}$ & $\begin{array}{c}\text { Eastern Canada- } \\
\text { Greenland DJF SAT }\end{array}$ & $\begin{array}{c}\text { Siberia } \\
\text { DJF SAT }\end{array}$ & $\begin{array}{c}\text { Siberia DJF } \\
\text { T10p }\end{array}$ & $\begin{array}{l}\text { East Asia } \\
\text { DJF SAT }\end{array}$ & $\begin{array}{l}\text { East Asia } \\
\text { DJF T10p }\end{array}$ \\
\hline BKS ON & -0.56 & 0.29 & -0.07 & -0.43 & 0.52 & -0.5 & 0.26 & -0.23 \\
\hline BKS DJF & 0.0 & -0.22 & -0.65 & 0.12 & 0.26 & -0.18 & 0.38 & -0.21 \\
\hline $\begin{array}{l}\text { Baffin Bay/Labrador } \\
\text { Sea ON }\end{array}$ & -0.02 & 0.3 & 0.1 & -0.47 & -0.21 & 0.33 & -0.13 & 0.04 \\
\hline $\begin{array}{l}\text { Baffin Bay/Labrador } \\
\text { Sea DJF }\end{array}$ & -0.33 & 0.31 & 0.25 & -0.78 & 0.0 & 0.08 & -0.25 & 0.11 \\
\hline
\end{tabular}

that the WACE pattern matched an increased occurrence of the positive phases of the two atmospheric circulation modes on intraseasonal scales. This is also consistent with previous studies that found an increased blocking frequency over the Ural region during 1979_ 2013 (e.g., Luo et al. 2016a).

\section{b. Drivers of intraseasonal surface temperature variability in the Arctic}

Winter SAT variability in the Arctic region is driven strongly by downward longwave radiation (DLW), which relates to the poleward transport of heat and moisture (e.g., Graversen et al. 2011; Woods et al. 2013; Graversen and Burtu 2016; Lee et al. 2017; Messori et al. 2017; Messori et al. 2018). In particular, recent studies have examined the impacts of different NAO phases with or without the concomitant presence of Ural blocking on poleward moisture intrusions and DLW (e.g., Gong and Luo 2017; B. Luo et al. 2017). Here, we analyze the link between poleward moisture flux and the DLW/SAT in the context of the two atmospheric circulation modes described in section 3 . Since surface

Seasonal-mean Z500 projection index/Events based on daily-Z500 projection

(a) DJF Z500_EOF1 seasonal-mean projection index/events

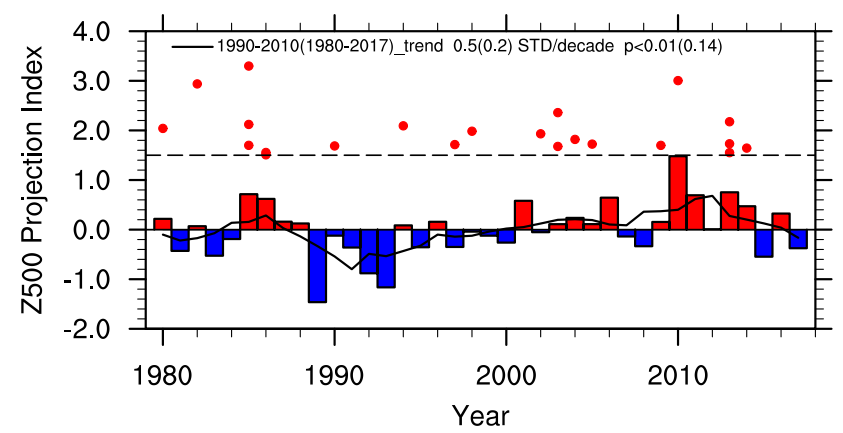

(b) DJF Z500_EOF2 seasonal-mean projection index/events

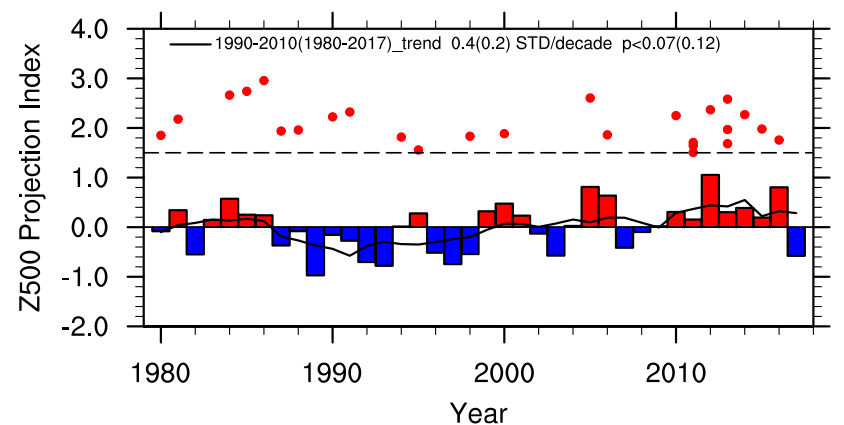

FIG. 7. DJF-mean Z500 daily projection index (bars) for (a) Z500-PC1 and (b) Z500-PC2. Filled circles denotes events with the maximum daily projection index (shown as $y$-axis values) above $1.5 \sigma$. The detailed procedures for computing the daily projection index and detecting events are provided in section $2 \mathrm{~b}$. Solid black lines represent 5-yr running averages of the seasonal-mean daily projection indices. Trends of the solid black lines are indicated in the legends. 

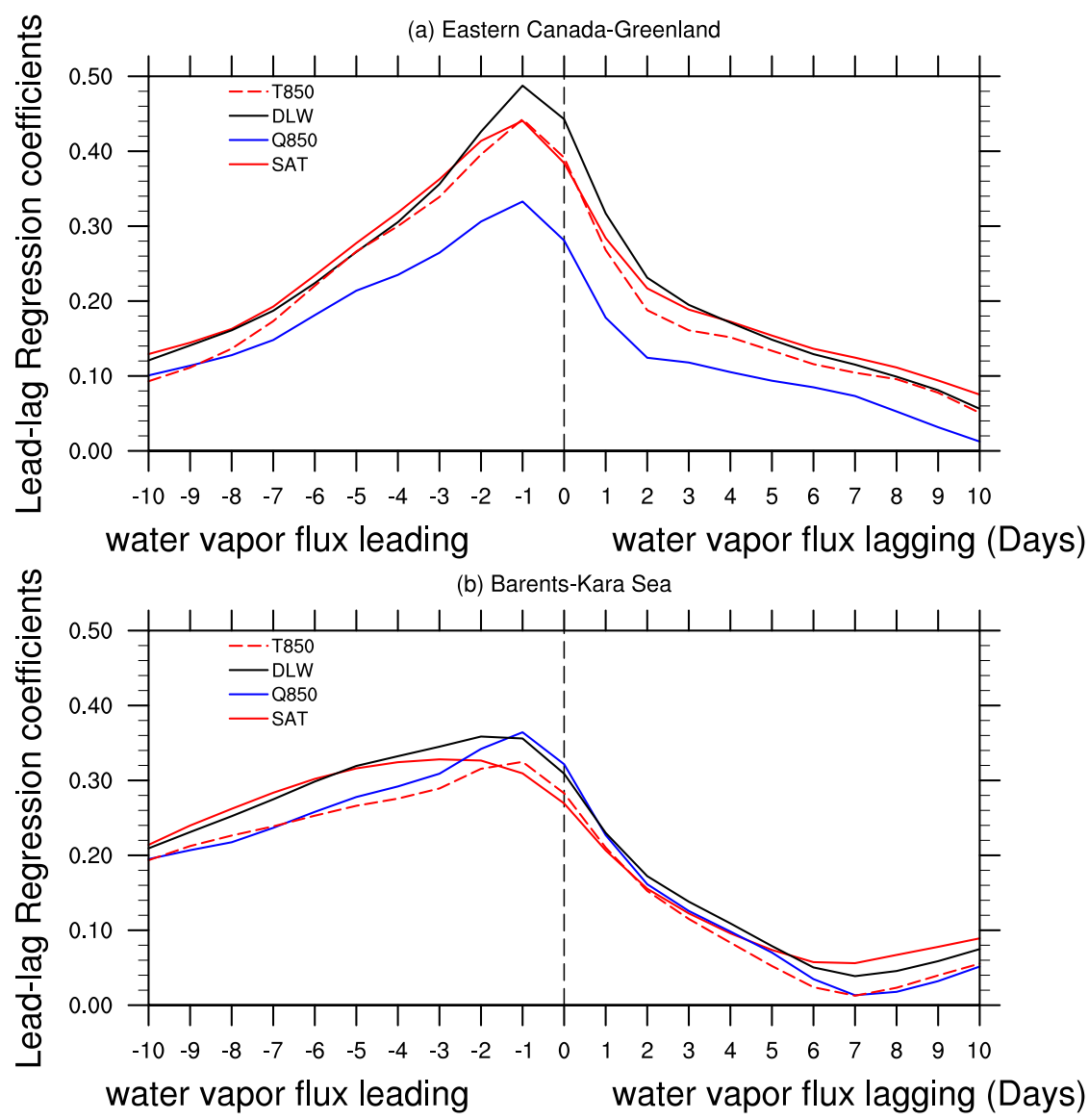

FIG. 8. Lead-lag regression coefficients of SAT (solid red), specific humidity at $850 \mathrm{hPa}$ (Q850; solid blue), surface downward longwave radiation (DLW; solid black), and air temperature at $850 \mathrm{hPa}$ (T850; dashed red) against vertically integrated northward water vapor flux along (a) $40^{\circ}-100^{\circ} \mathrm{W}$ at $65^{\circ} \mathrm{N}$ and (b) $20^{\circ}-65^{\circ} \mathrm{E}$ at $65^{\circ} \mathrm{N}$. All fields are normalized with respect to their standard deviations prior to computing the regressions.

DLW is tightly coupled to the SAT (Vargas Zeppetello et al. 2019), we do not attempt to distinguish cause and effect between the two, nor do we seek to separate the SAT anomalies due to the DLW anomalies that are purely forced by the atmospheric circulation from the contribution by the SAT-DLW coupling. The lead-lag regression coefficients of area-mean 850 -hPa temperature (T850), DLW, 850-hPa specific humidity (Q850), and SAT against the vertical integral of the atmospheric moisture flux along $65^{\circ} \mathrm{N}, 40^{\circ}-100^{\circ} \mathrm{W}$ for eastern Canada-Greenland (Fig. $8 \mathrm{a}$ ) and along $65^{\circ} \mathrm{N}, 20^{\circ}-65^{\circ} \mathrm{E}$ for the BKS (Fig. 8b) are computed. In eastern CanadaGreenland, the maximum regression coefficient for all variables is found when the atmospheric moisture flux leads by 1 day (i.e., lag -1 in Fig. 8a). Similar relationships can be found for T850, DLW, Q850, and SAT in the BKS (Fig. 8b). However, the regression coefficient of SAT peaks when atmospheric moisture flux leads by 2 days. These results point to the poleward moisture flux driving Arctic SATs. We leverage this in section 5c below to better understand the physical processes associated with the evolution of the two atmospheric circulation modes and their impacts on the Arctic SAT.

\section{c. Life cycles of the two atmospheric circulation modes}

To analyze the life cycle of the two circulation modes, composites of SLP, Z500, WAF, moisture flux, DLW and SAT are constructed with respect to the peak daily Z500-D1/D2 (day 0) over the positive events (see section 2b and Figs. 7, 9, 10, S4, and S5). A similar analysis can be found in Luo et al. (2016b) and Gong and Luo (2017), but we focus here on positive events of the two atmospheric circulation modes rather than specifically on Ural blocking events. At the same time, as also noted in Fig. 2, the Z500-PC2 exhibits a relatively strong correlation with blocking frequency across northern Eurasia, including the Ural region. 


\section{Composites wrt. Max Z500_projection_index Z500 EOF1}

(a) SLP/Z500/WAF250 -9

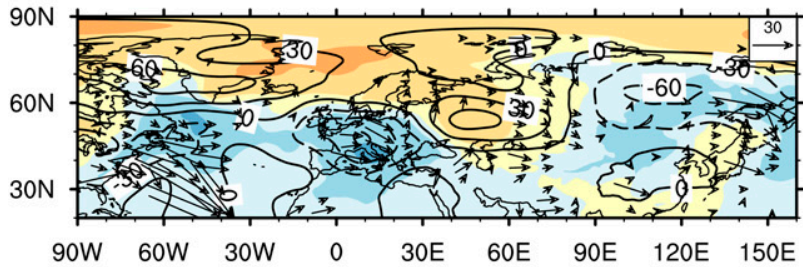

(c) SLP/Z500/WAF250 -3

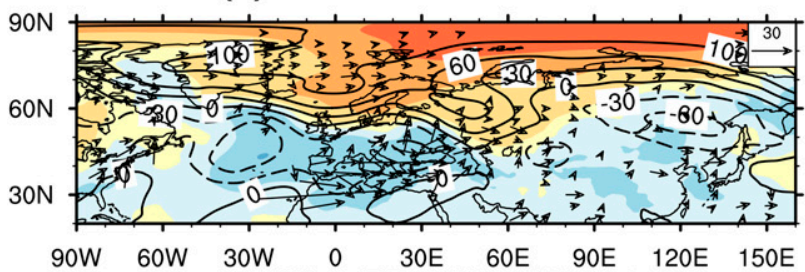

(e) SLP/Z500/WAF250 0

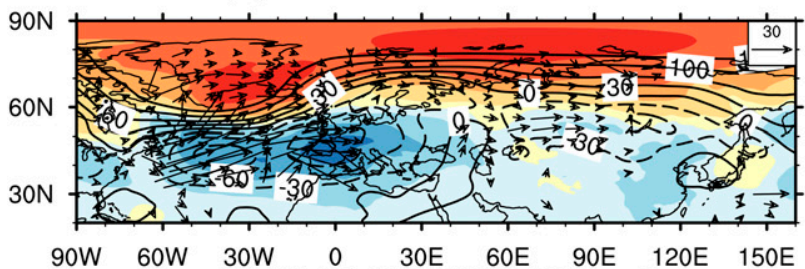

(g) SLP/Z500/WAF250 +3

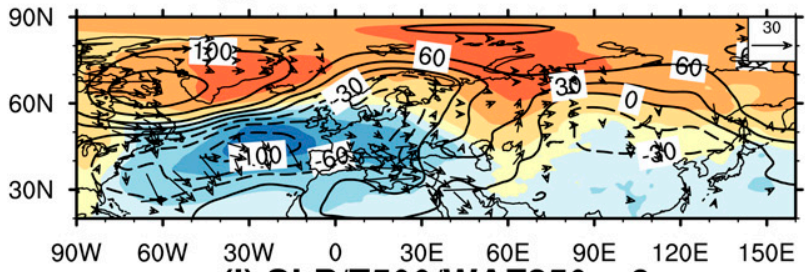

(i) SLP/Z500/WAF250 +9

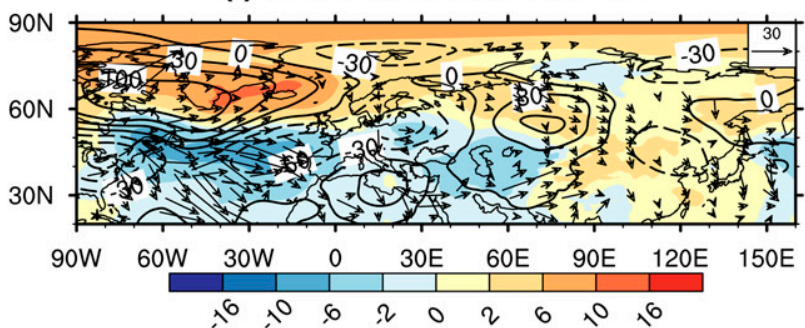

(b) WVF/DLW/SAT -9

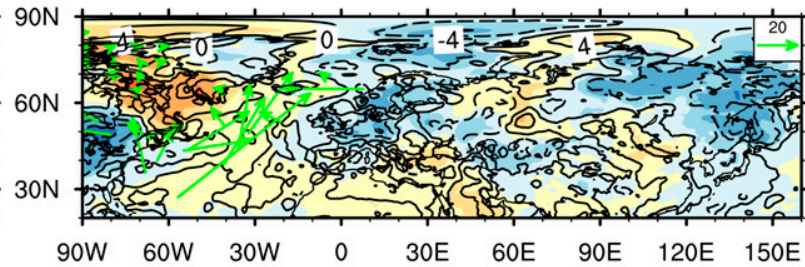

(d) WVF/DLW/SAT -3

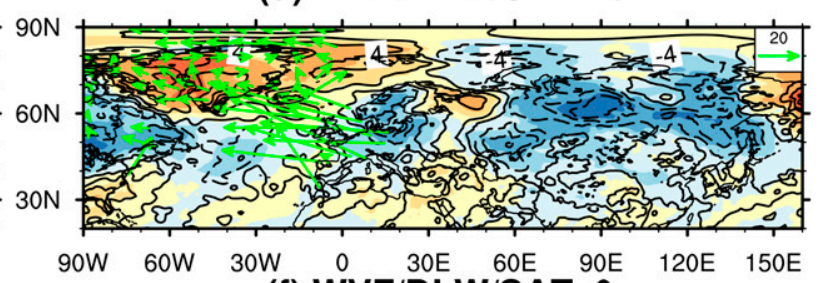

(f) WVF/DLW/SAT 0

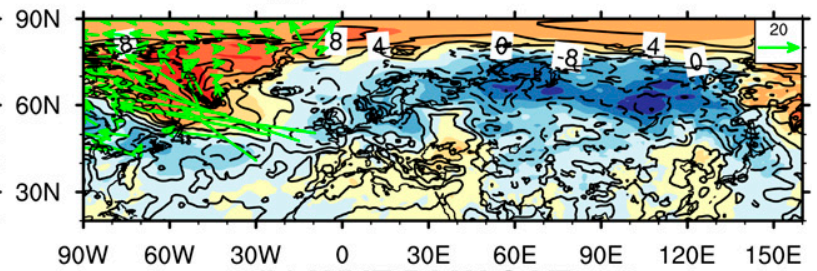

(h) WVF/DLW/SAT +3

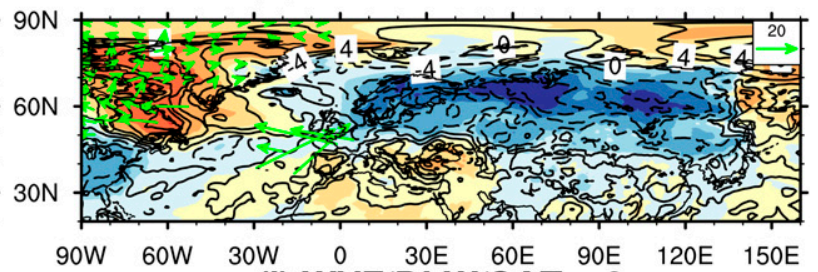

(j) WVF/DLW/SAT +9

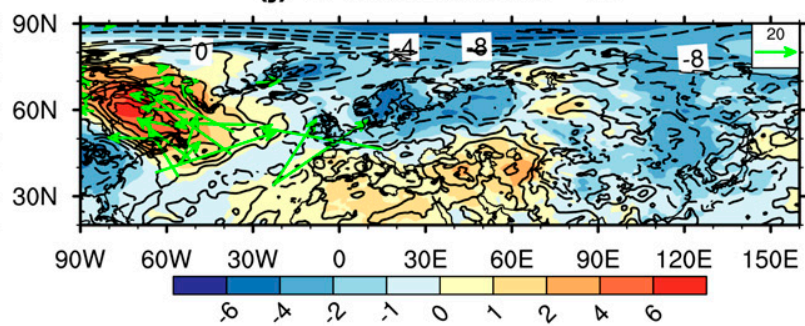

FIG. 9. Composite anomalies of various atmospheric fields based on the positive events of the first Z500 mode. Days lagging or leading the events (indicated at the top of each panel) are determined with respect to the day when the pattern projection index is largest (day 0 ). (left) SLP (shading; hPa), Z500 (contours; gpm), and wave activity flux at $250 \mathrm{hPa}$ (WAF250; only vectors with positive zonal component are displayed; $\mathrm{m}^{2} \mathrm{~s}^{-2}$ ) anomalies. (right) Vertical integral of water vapor flux (WVF; arrows; only WVF vectors with a positive meridional component are displayed between $90^{\circ} \mathrm{W}-0^{\circ} \mathrm{E}, 45^{\circ}-90^{\circ} \mathrm{N} ; \mathrm{kg} \mathrm{m} \mathrm{s}^{-1}$ ), DLW (contours; $\mathrm{W} \mathrm{m}^{-2}$ ), and SAT (shading; K) anomalies.

1) The AO-Like CIRCUlation MOde (Z500-D1)

(i) Development and mature phase. A sizeable blocking-like anticyclonic anomaly is centered over south Greenland on day -9 (Fig. 9a, see also Fig. 3c). This circulation anomaly leads to moisture convergence, enhanced DLW, and surface warming over eastern Canada and part of Greenland. Waves emanate from the region to the east of the United States and Canada (vectors, Fig. 9a), leading to a net wave activity flux convergence over the Atlantic. On day -3, a largely barotropic dipole circulation pattern is seen in both SLP 


\section{Composites wrt. Max Z500_projection_index Z500 EOF2}

(a) SLP/Z500/WAF250 -9

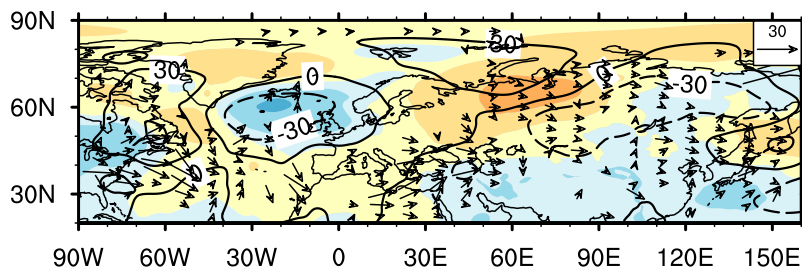

(c) SLP/Z500/WAF250 -3

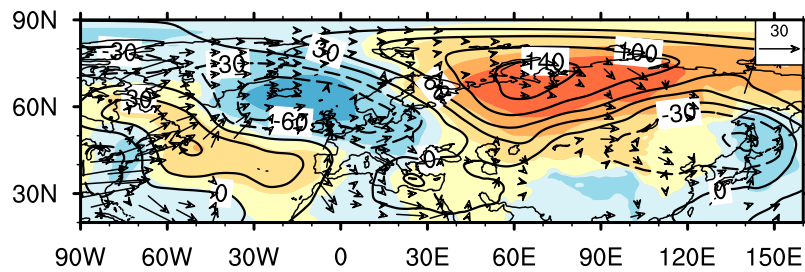

(e) SLP/Z500/WAF250 0

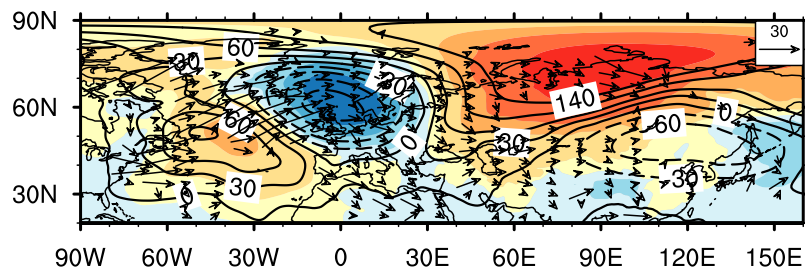

(g) SLP/Z500/WAF250 +3

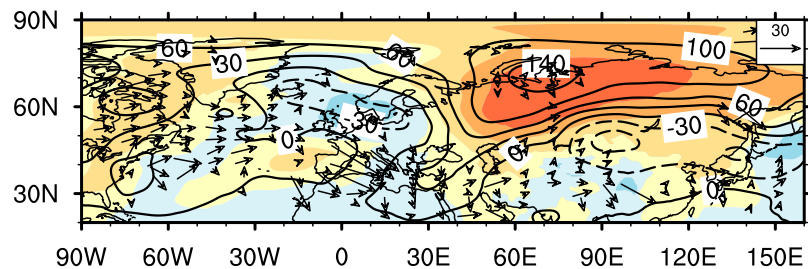

(i) SLP/Z500/WAF250 +9

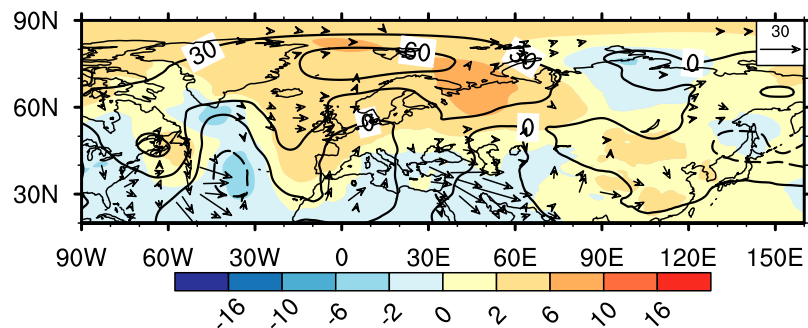

(b) WVF/DLW/SAT -9

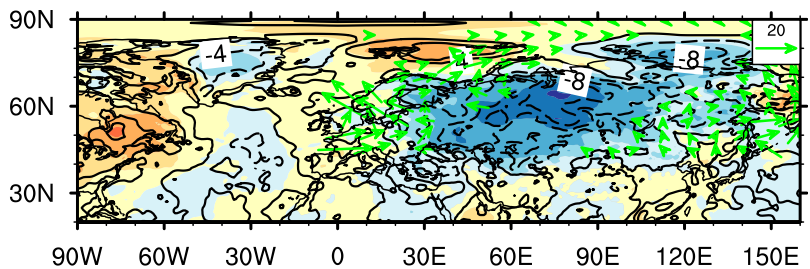

(d) WVF/DLW/SAT -3

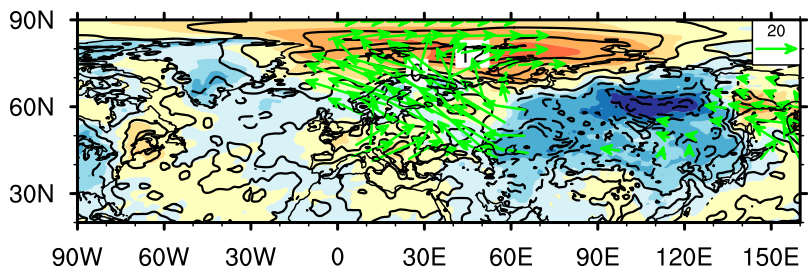

(f) WVF/DLW/SAT 0

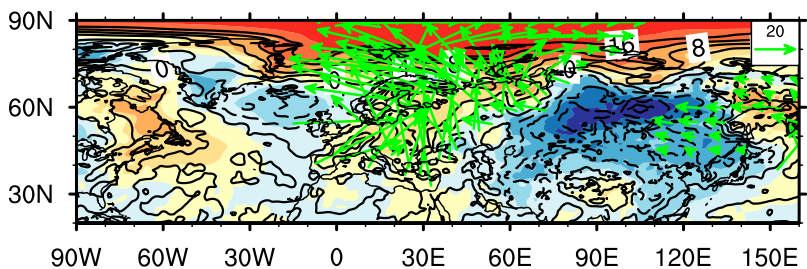

(h) WVF/DLW/SAT +3

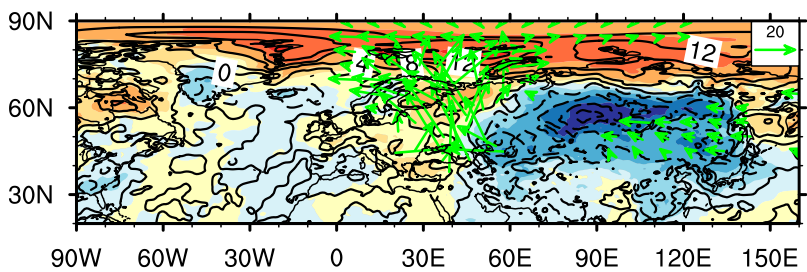

(j) WVF/DLW/SAT +9

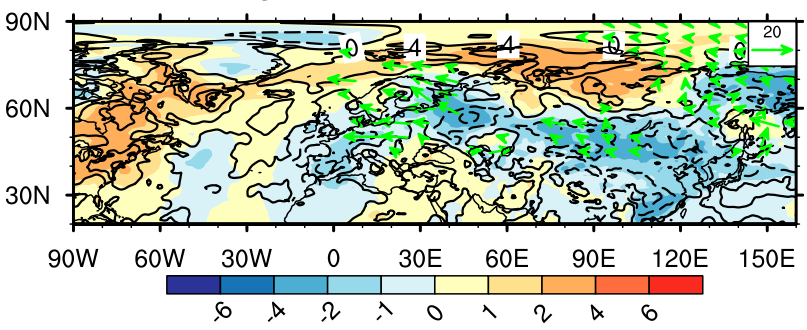

FIG. 10. As in Fig. 9, but for positive events of the second Z500 mode. Only WVF vectors with a positive meridional component are displayed between $0^{\circ}-150^{\circ} \mathrm{E}, 45^{\circ}-90^{\circ} \mathrm{N}$.

and Z500 anomalies (Fig. 9c). At the peak of the event, a hemisphere-wide dipole in Z500/SLP is seen, corresponding to a negative NAO over the North Atlantic (Fig. 9e). A strong WAF emanates from the North Atlantic and Greenland and propagates poleward. The poleward propagation may contribute to strengthening the anticyclonic anomaly over the Arctic (similar to the poleward wave propagation associated with cyclonic wave breaking, which drives negative NAO events and an anticyclonic anomaly over Iceland; e.g., Benedict et al. 2004). During the same period, from day -9 to day 0 , the above circulation features lead to stronger water vapor transport toward eastern Canada-Greenland (vectors, Figs. 9b,d,f), and large positive DLW and SAT anomalies in the region (contours and shading, respectively, in Figs. 9b,d,f). The warming also extends to the 
BKS. The circulation anomalies lead to opposite DLW and SAT features in northern Eurasia, due to the weaker airmass advection from the North Atlantic.

(ii) Decay phase. A strong ridge is evident over Siberia and the surrounding areas on day +3 (Fig. 9g). The anticyclonic circulation is shifted to the west over Baffin Bay. This leads to weaker water vapor transport (vectors, Figs. 9h,j), a smaller DLW anomaly, and a weaker warming (contours and shading, respectively, Figs. 9h,j) over Greenland. Stronger water vapor transport, larger DLW anomalies and a stronger warming are instead found over the Baffin Bay/Labrador Sea. At the same time, the cold anomalies in northern Eurasia intensify and extend southward in the following days. This is caused by a ridge over western Russia followed by the weakening of the high-latitude anticyclonic anomalies in Z500 and SLP, which favors the southward penetration of cold Arctic air masses. Such evolution likely accounts for the close relation between the Z500-PC1 circulation mode and the frequency of T10p in Siberia (Fig. 4b). On day +9 , the cyclonic anomaly in the North Atlantic weakens significantly and the anticyclonic anomaly over Baffin Bay effectively blocks the moisture transport toward Greenland and the surrounding region (Fig. 9i). Both the warming anomalies in eastern Canada and Greenland and cooling anomalies in northern Eurasia also weaken.

(iii) Temporal evolution of climate indices. While the northward moisture flux (solid green curve, Fig. 11a) and the NAO index (dashed green curve) are in phase with Z500-D1, other parameters such as DLW (solid blue curve) and SAT (solid red curve) lag by about one day in eastern Canada-Greenland. The maximum in Q850 (dashed blue curve) is found from day -1 to day +1 . The SATs in Siberia (dashed red curve) and East Asia (short-dashed red curve) lag the circulation pattern index by several days. The largest anomalies in SAT in the decay period are associated with the establishment of the ridge over western Russia as discussed above. Similarly, the enhancement of the SH (solid black curve) is found mostly during the decay period, in association with strong cold anomalies in northern Eurasia. The net impacts during the entire period on the $\mathrm{SH}$ are thus small. This explains the low correlation between the Z500-PC1 and the SH index (Table 1).

\section{2) THE MID-HIGH-LATITUDE WAVELIKE} CIRCULATION MODE (Z500-D2)

(i) Development and mature phase. A weak wave pattern is seen over the North Atlantic-Eurasian sector on day -9 (Fig. 10a). The wave structure significantly strengthens in the following days (Fig. 10c). In its mature phase, a well-defined wave structure is seen, accompanied by a strong eastward WAF propagation (Fig. 10e). The wave source is over the western North Atlantic, and the waves are absorbed in the BKS region and northern Eurasia. Wave trains emanating from the North Atlantic can interact with surface highs over Eurasia, modulating their strength and location through a complex interplay (cf. Takaya and Nakamura 2005; Sung et al. 2018). In our composites, the wave propagation is concomitant to the intensification of a broad high-pressure region spanning northern Eurasia and a strengthening of the water vapor transport toward BKS and the surrounding areas, leading to stronger DLW (Figs. 10c-f). The high pressure likely reflects blocking activity across a broad swath of northern Eurasia, in agreement with previous studies highlighting the contribution of blocking to the emergence of the WACE pattern (Luo et al. 2016a,b). However, we note that the anomaly is more geographically extended than the Ural blocking shown in Luo et al. (2016a,b). The circulation anomalies over the North Atlantic indicate the development of a positive NAO, as also discussed in previous studies (Luo et al. 2016b; Gong and Luo 2017). In a study by Sato et al. (2014), a similar wave pattern is excited by the oceanic front in the Gulf Stream region, which leads to warming in the Arctic and a cooling over northern Eurasia. However, the cyclonic anomaly over the North Atlantic sector in our study is located farther to the east. Concurrent changes include warming over the BKS and surrounding areas and a cooling in Siberia and East Asia. The cooling anomalies are contributed to by the cold advection from the Arctic region induced by the sizable blocking high anomaly. The cold anomalies reach as far as southern China. Similar anticyclonic circulations have been associated with cold air outbreaks in East Asia and Japan (Hori et al. 2011).

(ii) Decay. The wave structure decays in the following days (Figs. 10g,i), as do the anomalies of water vapor transport, DLW, and SAT over the BKS and the surrounding areas (Figs. 10h,j). The decay of the wave structure is mirrored in the WAF over the North Atlantic. Importantly, the cooling anomalies over East Asia and south China are still strong, due to the persistence of the positive Eurasian SLP anomaly and the continued northerly cold air advection.

(iii) Temporal evolution of climate indices. The northward moisture flux (solid green curve, Fig. 11b) and the NAO index (dashed green curve) are in phase with Z500-D2. The simultaneous growth of the positive NAO structure and the blocking high over northern 
(a) Composites wrt. Max Z500_projection_index Z500 EOF1

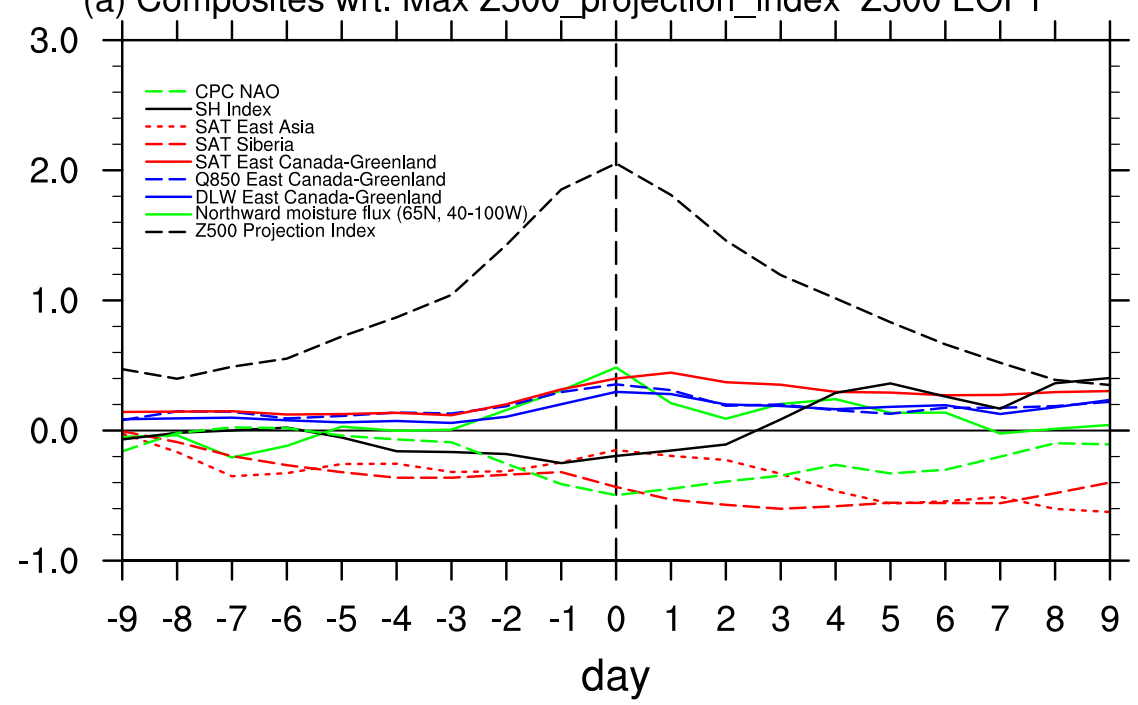

(b) Composites wrt. Max Z500_projection_index Z500 EOF2

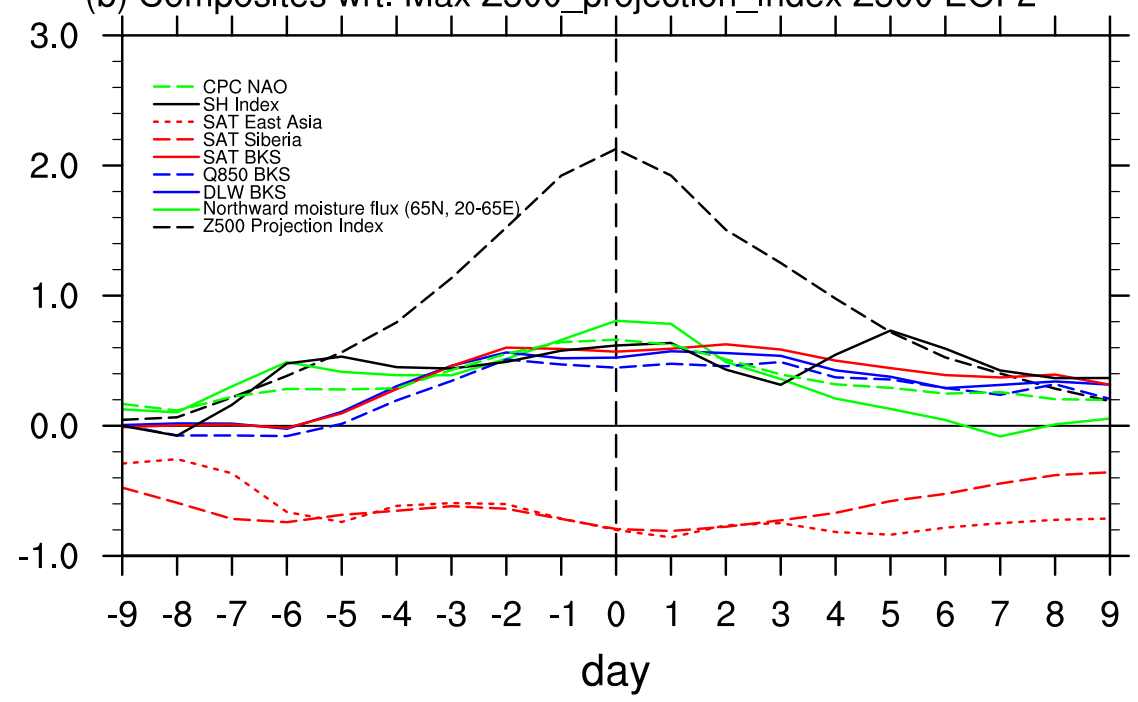

FIG. 11. Temporal evolution from day -9 to day +9 of area-mean composite anomalies as shown in Figs. 9 and 10 with respect to the positive events of (a) the first Z500 and (b) the second Z500 modes. Also depicted are Siberian high (SH) index (solid black curve), Q850 (dashed blue curve), Z500 projection index (dashed black curve), and northward WVF (solid green curve) along a particular longitudinal section $\left[40^{\circ}-100^{\circ} \mathrm{W}\right.$ at $65^{\circ} \mathrm{N}$ for (a) and $20^{\circ}-65^{\circ} \mathrm{E}$ at $65^{\circ} \mathrm{N}$ for (b)]. See text for the definition of the $\mathrm{SH}$ index. All fields are normalized with respect to their standard deviations. Domains for eastern Canada-Greenland and BKS are $10^{\circ}-90^{\circ} \mathrm{W}, 55^{\circ}-80^{\circ} \mathrm{N}$ and $30^{\circ}-110^{\circ} \mathrm{E}, 70^{\circ}-85^{\circ} \mathrm{N}$, respectively. Domains for Siberia and East Asia are $80^{\circ}-120^{\circ} \mathrm{E}, 50^{\circ}-65^{\circ} \mathrm{N}$ and $80^{\circ}-120^{\circ} \mathrm{E}, 40^{\circ}-50^{\circ} \mathrm{N}$, respectively.

Eurasia is slightly different from previous studies that find the positive NAO preceding the growth of a Ural blocking high (Gong and Luo 2017), and reflects the difference between the analyzed atmospheric circulation modes. In contrast, the DLW (solid blue curve) and SAT (solid red curve) in BKS lag Z500-D2 by one and two days, respectively. Interestingly, the DLW and Q850 anomalies in the BKS (dashed blue line in Fig. 11b) remain relatively stable between about day -2 and day +3 . This leads to relatively strong SAT anomalies in the region during the same period. The cooling anomalies in East Asia are strongest during the decay phase of the events. This relates to the strong intensification of the SH during the decay phase, although some degree of intensification is seen throughout the life cycle of the mode, accounting for the high correlation between Z500-PC2 and the SH index (Table 1). 
(a) Composites wrt. Max Z500_projection_index Z500 EOF1 East Canada-Greenland

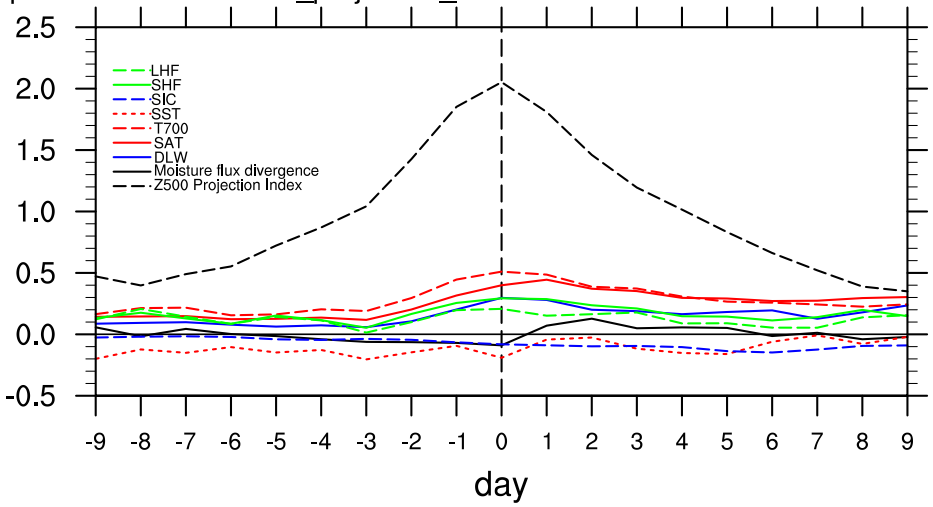

(b) Composites wrt. Max Z500_projection_index Z500 EOF2 BKS

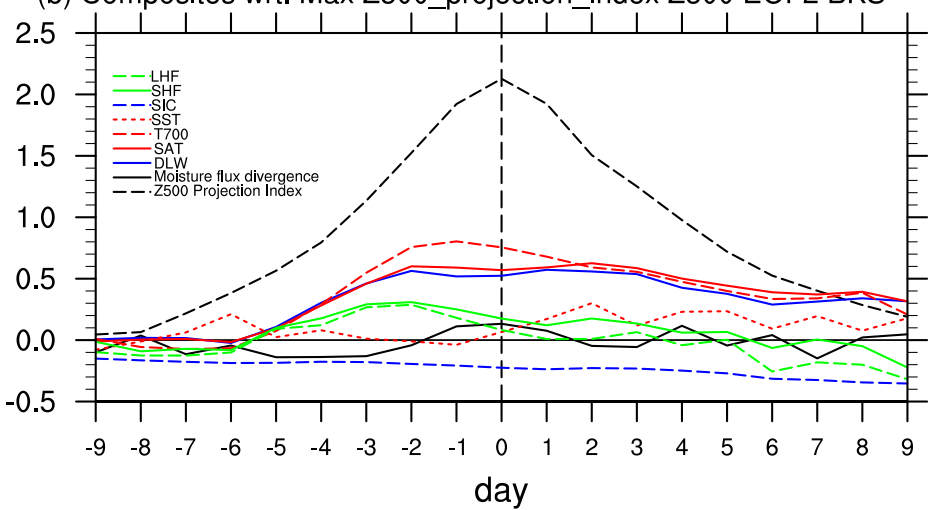

FIG. 12. As in Fig. 11, but where different atmospheric variables are plotted. These include sensible heat flux, latent heat flux, sea ice concentration, and moisture flux divergence. Domains for eastern Canada-Greenland and BKS are $10^{\circ}-90^{\circ} \mathrm{W}, 55^{\circ}-80^{\circ} \mathrm{N}$ and $30^{\circ}-110^{\circ} \mathrm{E}, 70^{\circ}-$ $85^{\circ} \mathrm{N}$, respectively. Only the turbulent heat fluxes over the Arctic Ocean are considered in the domain average.

\section{The impact of Arctic sea ice on the WACE pattern}

a. The role of Arctic sea ice in the warming associated with the two atmospheric circulation modes on intraseasonal scales

Arctic sea ice can potentially influence local and remote SATs on intraseasonal time scales. It is therefore important to examine whether the influence of the two atmospheric circulation modes on the SATs is associated with anomalies in sea ice cover that in turn may affect SSTs and turbulent heat fluxes. In eastern CanadaGreenland, a negative moisture flux divergence (i.e., convergence) anomaly is seen mostly during the intensification of the first atmospheric circulation mode (Fig. 12a; solid and dashed black curves), with peak at day 0 . Both the DLW (solid blue curve) and temperature anomalies (solid red curve) peak the day after. The SIC exhibits weak decreases throughout the period and specifically during the decay of the circulation mode (dashed blue curve). In association with the slight decreases in sea ice, the SST (short-dashed red curve) is characterized by a weak cooling. However, the turbulent heat fluxes (dashed and solid green curves; note that downward fluxes are positive and only the turbulent heat fluxes over the Arctic Ocean are considered in the domain average) have relatively large positive anomalies, in phase with the circulation mode. Both the timing and the sign of the turbulent heat flux anomalies suggest that the SAT warming is not primarily influenced by the surface conditions (i.e., SST and SIC). In other words, the SAT warming in the Arctic region associated with the first circulation mode is primarily driven directly by the atmospheric circulation and the associated moisture/heat flux, rather than by local variations in sea ice cover.

In the BKS region, the strongest negative moisture flux divergence is seen on day -4 (solid black curve) and the moisture flux divergence exhibits pronounced variations in the following days. The T700 anomaly peaks at day -1 (long-dashed red curve) while the SAT (solid red curve) and DLW anomalies (solid blue curve) peak together at day 2. The turbulent heat fluxes (dashed and 
solid green curves) exhibit positive anomalies between day -5 and day 5 , with a peak at day -2 . The SIC decrease (dashed blue curve) gradually intensifies during the whole period. The SIC decrease is comparatively stable after day 9, with relatively large negative turbulent heat flux anomalies while the SAT anomalies weaken (Fig. S6b). The turbulent heat fluxes, and specifically the latent heat flux, display negative anomalies after day 5 in association with relatively large sea ice loss. However, this occurs during the decay phase of the circulation mode, and positive turbulent heat flux anomalies are seen throughout most of the life cycle of the circulation mode. By the same reasoning as above, we thus argue that the SAT warming in the BKS region associated with the second circulation mode is primarily driven directly by the atmospheric circulation and the associated moisture/heat flux.

\section{b. Winter Arctic sea ice loss}

Winter-mean sea ice cover in both the BKS and Baffin Bay/Labrador Sea regions correlates relatively closely with SATs, but weakly with the Z500-PC1/PC2 (Table 3). This suggests potentially independent impacts of the atmospheric modes and sea ice on Arctic SAT, in analogy to what was found on intraseasonal time scales (section 6a). The apparent decoupling of the winter sea ice variability from the two atmospheric circulation modes may be partly explained by the strong link of winter SIC to the preceding autumn sea ice conditions $(r=0.62$ for the BKS and $r=0.7$ for the Baffin Bay/Labrador Sea region).

The winter sea ice in the BKS and Baffin Bay/ Labrador Sea has been decreasing in recent decades (Fig. 6b; see also Cavalieri and Parkinson 2012). The decrease in the BKS spans the whole 1980-2017 period, while the Baffin Bay/Labrador Sea region shows no evident trend after 2005. Their independent contribution to the Arctic warming during the recent WACE period (i.e., 1990-2010) can be estimated using the same method as for the circulation modes. The results indicate that the local winter sea ice loss accounts for $36.4 \%$ $(56 \%)$ of the recent warming trend in eastern CanadaGreenland (BKS), confirming the relevance of sea ice loss for the recent warming trend in the Arctic (Honda et al. 2009; Mori et al. 2014; Ogawa et al. 2018). Compared to the circulation modes, local sea ice cover changes thus drive a larger contribution to the warming trend in BKS but a smaller contribution in eastern Canada-Greenland. However, the correlation between sea ice cover and Eurasian SATs is very weak, with only winter sea ice in BKS exhibiting a moderate correlation with winter SAT in East Asia (Table 3). Moreover, this moderate correlation may not indicate that the winter BKS sea ice leads to cold winters in East Asia. A regression analysis for the winter BKS sea ice finds persistent circulation anomaly patterns over autumn and winter in the Northern Hemisphere extratropics, including an anticyclonic anomaly over BKS-northern Russia (Fig. S7). This suggests that the circulation anomaly patterns driving the cooling anomalies in East Asia are not due to the winter BKS sea ice forcing. Note that these regression circulation patterns are different from the two circulation modes.

This analysis comes with two caveats. First, sea ice variability is also impacted by the atmospheric circulation and thus the trend contribution of the Arctic sea ice to Arctic SATs may be overestimated. Second, we have not considered potential feedbacks of the winter sea ice loss onto the two atmospheric circulation modes-for example, through the modulation of Ural blocking frequency (Luo et al. 2016a) or lagged effects. However, as discussed above such feedbacks are likely weak, at least for the two circulation modes considered in the present study.

\section{c. Autumn Arctic sea ice loss}

The autumn sea ice in BKS correlates strongly with the Z500-PC1 $(r=-0.56)$ but weakly with the Z500PC2 $(r=0.29$; Table 3$)$. It also exhibits relatively strong relationships with the SAT in eastern CanadaGreenland and Siberia. In contrast, the autumn sea ice in Baffin Bay/Labrador Sea correlates weakly with both circulation modes. The role of BKS autumn sea ice in driving the winter atmospheric circulation variability is still debated, as a wide range of atmospheric responses to Arctic sea ice forcing are found in model experiments (Cohen et al. 2014). To further examine the association between the autumn BKS sea ice and the two atmospheric circulation modes, histograms of the Z500-D1/ D2 as well as the joint probability distribution with respect to low and high sea ice years are displayed in Fig. 13 for detrended fields. The distribution of the Z500-D1 is systematically shifted toward positive values in low sea ice years (10 lowest years) compared to high sea ice years (10 highest years) in the BKS (Fig. 13a). This suggests that the positive phase of the Z500-EOF1 pattern tends to occur more frequently and/or with greater intensity during winters preceded by low sea ice cover in the BKS, as also emphasized by the shift toward more positive values in the joint probability density distribution (cf. Figs. 13c,d). Such relationship is not found for Z500-D2 (Figs. 13b,c,d). This relationship is discussed further in section 7 .

\section{Discussion and conclusions}

We have identified two distinct modes of winter atmospheric circulation over the North Atlantic-northern 
Histogram Daily Z500-EOF1/EOF2 Projection Index
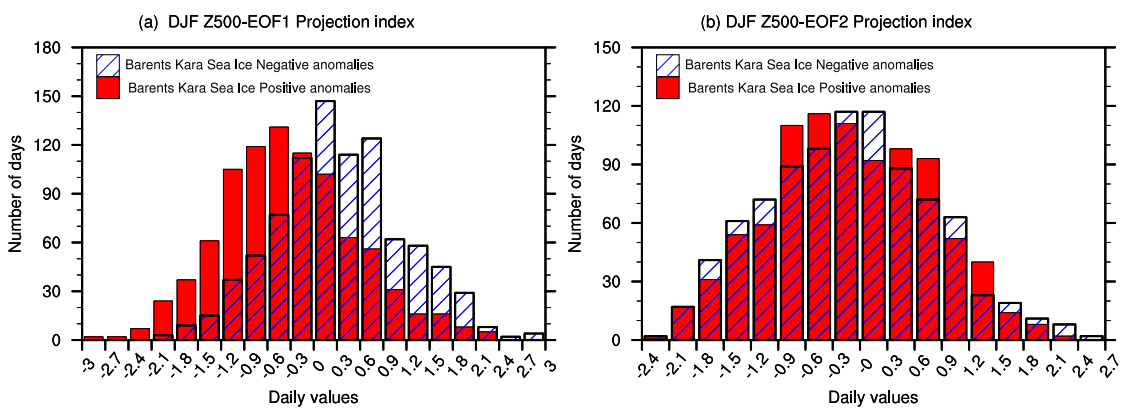

Z500-EOF1/EOF2 Projection Index joint probability density distribution
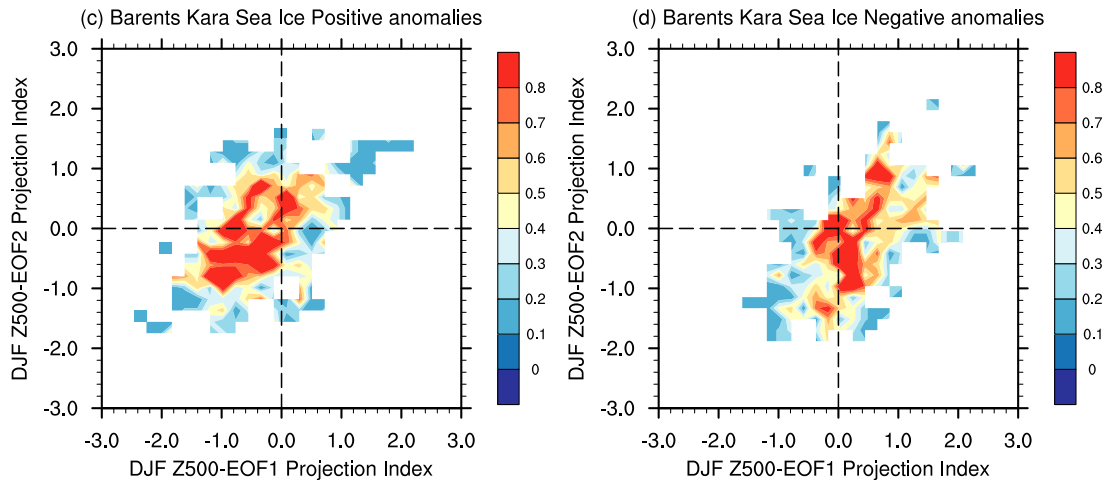

FIG. 13. (top) Histogram of daily projection index of (a) Z500-EOF1 and (b) Z500-EOF2 during 1980-2017 with respect to low and high BKS sea ice years for October and November during 1979-2016. (bottom) Joint probability density distribution of daily projection indexes of Z500-EOF1/EOF2 during 1980-2017 with respect to (c) high and (d) low BKS sea ice years for October and November during 1979-2016.

Eurasia that contributed to the WACE pattern during 1990-2010. The first mode resembles the AO/NAO pattern and Greenland blocking, albeit with regional differences. The second mode is characterized by a stationary wave pattern at mid-high latitudes and correlates strongly with atmospheric blocking frequency in northern Eurasia. Both modes reflect circulation features identified in previous studies looking at Eurasian and Arctic SAT anomalies (Luo et al. 2016a; Zhong et al. 2018).

The two modes exhibit significant upward trends during the 1990-2010 WACE period that weaken or reverse after 2010. Our analysis indicates that both circulation modes contribute to the WACE pattern, albeit in different ways. The AO-like circulation mode explains a large portion of the surface warming trend in eastern Canada-Greenland and the majority of the cooling trend in Siberia. This circulation mode also exhibits a close relationship with the frequency of daily temperature extremes over northern Eurasia. The second circulation mode instead accounts for a large portion of the surface warming trend in the BKS region. It also contributes strongly to the cooling trend in East
Asia (about twice as much as the first circulation mode) and correlates strongly with the $\mathrm{SH}$ intensity. Collectively, these two circulation modes explain a substantial portion of the Arctic warming trend and the majority of the Eurasian cooling trend during the recent WACE period (1990-2010). The local Arctic sea ice variability during winter is relatively independent of the two circulation modes and roughly accounts for the missing portion of the Arctic warming trend.

The origin of the recent trends in the two circulation modes has not been addressed in the present study. The greenhouse effect may not be the major driver of decadal AO/NAO variability (Gillett and Fyfe 2013), and indeed the recent downward trend in the NAO may be primarily driven by tropical SST anomalies (Ding et al. 2014). The strong association between the NAO/AO and the first circulation mode discussed in the present study suggests that its recent trend could also be relatively independent of anthropogenic forcing. Regarding the second circulation mode, similar mid-high-latitude wavelike structures can be found in Sato et al. (2014) and Sung et al. (2018). The driving mechanisms of such patterns are warming SSTs in the Gulf Stream region in 
the former study and changes in mean-flow condition in the North Atlantic in the latter [see also discussion in section $5 \mathrm{c}(2)]$. The exact driving mechanism for the second circulation mode should be studied further.

Winter-mean values of daily indices of the two modes are consistent with the two principal components in terms of recent upward trends. This suggests that recurring intraseasonal atmospheric circulation patterns resembling these two circulation modes play an important role in driving the recent WACE pattern. The second mode resembling a wavelike pattern is likely also a strong driver of the recent intensification of the $\mathrm{SH}$ (Jeong et al. 2011). We have further analyzed the intraseasonal evolution of the two circulation modes. Their growth and decay exert a strong influence on the meridional moisture advection pathways, which in turn affect the surface radiation and thus the temperature over the Arctic region. Their impact on the cold temperature anomalies over the Eurasian continent is mediated by atmospheric blocking anomalies and the resulting northerly cold air advection.

The interplay between the atmospheric circulation modes and sea ice cover is partly still an open question. While we found the variability of winter sea ice in the Arctic to be relatively independent of the two modes, they can modulate temperatures in the region and hence have a lagged effect on sea ice. In recent years (from about 2010), the warming trend in both the BKS and eastern Canada-Greenland has largely ceased, with even a weak cooling trend seen in the latter (Fig. 6a). The downward trend in Z500-PC2 over these years (Fig. 1d) may explain the hiatus of the BKS warming, by offsetting the expected warming caused by the decreasing trend in BKS sea ice (Fig. 6b). The downward trend in Z500-PC1 (Fig. 1b), along with the seemingly stable sea ice cover in the Baffin Bay/Labrador Sea (Fig. 6b), may explain the cooling trend in eastern Canada-Greenland. On the other hand, the sea ice itself may affect the circulation modes, and indeed we found a significant correlation between autumn BKS sea ice cover and Z500-PC1. This raises the question of whether the upward trend in Z500-PC1 during the WACE period and the subsequent decline may be partly driven by autumn sea ice loss. Arctic sea ice variability has been associated with $\mathrm{AO} / \mathrm{NAO}-$ like structures in both observations and model experiments. However, the forced atmospheric responses in model experiments are diverse (Cohen et al. 2014), suggesting a large uncertainty in this linkage. Furthermore, the Z500-PC1 has transitioned to a decreasing trend in recent years (Fig. 1b) notwithstanding the continued decrease in autumn BKS sea ice cover (Fig. 6b). In other words, the decreasing trend of autumn BKS sea ice cannot explain the abrupt change of the trend in Z500-PC1 in recent years. This indirectly suggests that the Arctic sea ice may not be a primary factor driving the decadal variations in Z500-PC1. In fact, the robustness of the linkage between the autumn BKS sea ice and the winter NAO has recently been questioned (Kolstad and Screen 2019; Blackport and Screen 2019). Moreover, both the November BKS sea ice loss and negative winter NAO can be forced by November Ural blocking anomalies (Peings 2019), which suggests that the relationship between them is generated by a common driver. Furthermore, Blackport et al. (2019) argue for minimal influence of reduced Arctic sea ice on cold winters in the midlatitudes (see also Fyfe 2019). Finally, with the apparent end of the positive trends in the two circulation modes around 2010, the Eurasian cooling trends characteristic of the WACE period have been replaced by warming trends.

We obtain a quantitative overview of these links by comparing the SAT trends over various regions for the period 1980-2017, as computed from the ERA-Interim data and reconstructed from the two circulation modes and the Arctic sea ice (Table 2). DJF sea ice in eastern Canada-Greenland (BKS) contributes strongly to local warming, more so than DJF Z500-PC1 (PC2). Thus, the local DJF sea ice plays an important role in the Arctic warming in both the long-term and the recent WACE period. The ERA-Interim winter cooling trend in Siberia and East Asia is extremely small, and broadly consistent with the trends reconstructed from the DJF Z500-PC1/PC2. However, the trends reconstructed from the October-November (ON)/DJF BKS sea ice indicate relatively strong winter cooling in Siberia and East Asia. Thus, BKS sea ice anomalies would lead to continuous cooling in Siberia and East Asia if it were the major driver of the winter temperature trends in these regions, suggesting that it is not a strong driver of the decadal winter cooling in Eurasia during the WACE period. This finding is broadly consistent with the results in Blackport et al. (2019), who found no impacts of Arctic sea ice on the recent midlatitude cold winters.

We conclude that the recent WACE pattern is strongly driven by two distinct atmospheric circulation modes. These account for the majority of the cooling trends over Eurasia and are relatively independent of the Arctic sea ice anomalies. The warming trend in the Arctic is partly contributed to by the two modes and partly driven by local sea ice loss. The upward trends in the two circulation modes, which largely ceased around 2010, may be a manifestation of decadal variability. Understanding their origin is useful both for unraveling the causes of the recent WACE pattern and for gleaning new insights into possible regional temperature trends in the coming decades. 
Acknowledgments. This study is supported by the APPLICATE project (727862), which is funded by the European Union's Horizon 2020 Research and Innovation Programme. KY is grateful to Orli Lachmy for her valuable comments and suggestions. GM was partly supported by the Swedish Research Council Vetenskapsrådet (Grant 2016-03724).

\section{REFERENCES}

Alexander, M. A., U. S. Bhatt, J. E. Walsh, M. S. Timlin, J. S. Miller, and J. D. Scott, 2004: The atmospheric response to realistic Arctic sea ice anomalies in an AGCM during winter. J. Climate, 17, 890-905, https://doi.org/10.1175/1520-0442(2004)017<0890: TARTRA $>2.0 . \mathrm{CO} ; 2$.

Barnes, E. A., 2013: Revisiting the evidence linking Arctic amplification to extreme weather in midlatitudes. Geophys. Res. Lett., 40, 4728-4733, https://doi.org/10.1002/grl.50880.

_ and J. A. Screen, 2015: The impact of Arctic warming on the midlatitude jet-stream: Can it? Has it? Will it? Wiley Interdiscip. Rev.: Climate Change, 6, 277-286, https://doi.org/ 10.1002/wcc.337.

Benedict, J. J., S. Lee, and S. B. Feldstein, 2004: Synoptic view of the North Atlantic Oscillation. J. Atmos. Sci., 61, 121-144, https:// doi.org/10.1175/1520-0469(2004)061<0121:SVOTNA > 2.0.CO;2.

Blackport, R., and J. A. Screen, 2019: Influence of Arctic sea ice loss in autumn compared to that in winter on the atmospheric circulation. Geophys. Res. Lett., 46, 2213-2221, https://doi.org/ 10.1029/2018GL081469.

$\_,-$, K. van der Wiel, and R. Bintanja, 2019: Minimal influence of reduced Arctic sea ice on coincident cold winters in mid-latitudes. Nat. Climate Change, 9, 697-704, https://doi.org/ 10.1038/s41558-019-0551-4.

Cattiaux, J., Y. Peings, D. Saint-Martin, N. Trou-Kechout, and S. J. Vavrus, 2016: Sinuosity of midlatitude atmospheric flow in a warming world. Geophys. Res. Lett., 43, 8259-8268, https:// doi.org/10.1002/2016GL070309.

Cavalieri, D. J., and C. L. Parkinson, 2012: Arctic sea ice variability and trends, 1979-2010. Cryosphere, 6, 881-889, https://doi.org/ 10.5194/tc-6-881-2012.

Chen, L., J. Francis, and E. Hanna, 2018: The "warm-Arctic/coldcontinents" pattern during 1901-2010. Int. J. Climatol., 38 5245-5254, https://doi.org/10.1002/joc.5725.

Cohen, J., J. Foster, M. Barlow, K. Saito, and J. Jones, 2010: Winter 20092010: A case study of an extreme Arctic Oscillation event. Geophys. Res. Lett., 37, L17707, https://doi.org/10.1029/2010GL044256.

- , and Coauthors, 2014: Recent Arctic amplification and extreme mid-latitude weather. Nat. Geosci., 7, 627-637, https:// doi.org/10.1038/ngeo2234.

Davini, P., C. Cagnazzo, R. Neale, and J. Tribbia, 2012: Coupling between Greenland blocking and the North Atlantic Oscillation pattern. Geophys. Res. Lett., 39, L14701, https://doi.org/ 10.1029/2012GL052315.

Dee, D., and Coauthors, 2011: The ERA-Interim reanalysis: Configuration and performance of the data assimilation system. Quart. J. Roy. Meteor. Soc., 137, 553-597, https://doi.org/ 10.1002/qj.828.

Ding, Q., J. M. Wallace, D. S. Battisti, E. J. Steig, A. J. E. Gallant, H.-J. Kim, and L. Geng, 2014: Tropical forcing of the recent rapid Arctic warming in northeastern Canada and Greenland Nature, 509, 209-212, https://doi.org/10.1038/nature13260.
Francis, J. A., and S. J. Vavrus, 2015: Evidence for a wavier jet stream in response to rapid Arctic warming. Environ. Res. Lett., 10, 014005, https://doi.org/10.1088/1748-9326/10/1/014005.

Fyfe, J. C., 2019: Midlatitudes unaffected by sea ice loss. Nat. Climate Change, 9, 649-650, https://doi.org/10.1038/s41558-0190560-3.

Gelaro, R., and Coauthors, 2017: The Modern-Era Retrospective Analysis for Research and Applications, version 2 (MERRA-2). J. Climate, 30, 5419-5454, https://doi.org/10.1175/JCLI-D-16-0758.1.

Gillett, N. P., and J. C. Fyfe, 2013: Annual mode changes in the CMIP5 simulations. Geophys. Res. Lett., 40, 1189-1193, https://doi.org/10.1002/grl.50249.

Gong, T., and D. Luo, 2017: Ural blocking as an amplifier of the Arctic sea ice decline in winter. J. Climate, 30, 2639-2654, https://doi.org/10.1175/JCLI-D-16-0548.1.

Graversen, R. G., and M. Burtu, 2016: Arctic amplification enhanced by latent energy transport of atmospheric planetary waves. Quart. J. Roy. Meteor. Soc., 142, 2046-2054, https:// doi.org/10.1002/qj.2802.

T. Mauritsen, S. Drijfhout, M. Tjernström, and S. Mårtensson, 2011: Warm winds from the Pacific caused extensive Arctic sea-ice melt in summer 2007. Climate Dyn., 36, 2103-2112, https://doi.org/10.1007/s00382-010-0809-z.

Harris, I., P. D. Jones, T. J. Osborn, and D. H. Lister, 2014: Updated high-resolution grids of monthly climatic observations-The CRU TS 3.1 dataset. Int. J. Climatol., 34, 623-642, https://doi.org/10.1002/joc.3711.

He, S., Y. Gao, F. Li, H. Wang, and Y. He, 2017: Impact of Arctic Oscillation on the East Asian climate: A review. Earth-Sci. Rev., 164, 48-62, https://doi.org/10.1016/j.earscirev.2016.10.014.

Honda, M., J. Inoue, and S. Yamane, 2009: Influence of low Arctic sea-ice minima on anomalously cold Eurasian winters. Geophys. Res. Lett., 36, L08707, https://doi.org/10.1029/2008GL037079.

Hori, M. E., J. Inoue, T. Kikuchi, M. Honda, and Y. Tachibana, 2011: Recurrence of intraseasonal cold air outbreak during the 2009/2010 winter in Japan and its ties to the atmospheric condition over the Barents-Kara Sea. SOLA, 7, 25-28, https:// doi.org/10.2151/sola.2011-007.

Hurrell, J. W., 1996: Influence of variations in extratropical wintertime teleconnections on Northern Hemisphere temperature. Geophys. Res. Lett., 23, 665-668, https://doi.org/10.1029/ 96GL00459.

Iles, C., and G. Hegerl, 2017: Role of the North Atlantic Oscillation in decadal temperature trends. Environ. Res. Lett., 12,114010, https://doi.org/10.1088/1748-9326/aa9152.

Inoue, J., M. E. Hori, and K. Takaya, 2012: The role of Barents Sea ice in the wintertime cyclone track and emergence of a warmArctic cold-Siberian anomaly. J. Climate, 25, 2561-2568, https://doi.org/10.1175/JCLI-D-11-00449.1.

Jeong, J. H., T. Ou, H. W. Linderholm, B. M. Kim, S. J. Kim, J. S. Kug, and D. Chen, 2011: Recent recovery of the Siberian high intensity. J. Geophys Res., 116, D23102, https://doi.org/10.1029/2011JD015904.

Johannessen, O. M., and Coauthors, 2004: Arctic climate change: Observed and modelled temperature and sea-ice variability. Tellus, 56A, 328-341, https://doi.org/10.1111/j.1600-0870.2004.00060.x.

Johnson, N. C., S. P. Xie, Y. Kosaka, and X. Li, 2018: Increasing occurrence of cold and warm extremes during the recent global warming slowdown. Nat. Commun., 9, 1724, https:// doi.org/10.1038/s41467-018-04040-y.

Kinnard, C., C. M. Zdanowicz, D. A. Fisher, E. Isaksson, A. De Vernal, and L. G. Thompson, 2011: Reconstructed changes in Arctic sea ice over the past 1,450 years. Nature, 479, 509-512, https://doi.org/10.1038/nature10581. 
Kolstad, E. W., and J. A. Screen, 2019: Non-stationary relationship between autumn Arctic sea ice and the winter North Atlantic Oscillation. Geophys. Res. Lett., 46, 7583-7591, https://doi.org/ 10.1029/2019GL083059.

Lee, S., T. Gong, S. B. Feldstein, J. A. Screen, and I. Simmonds, 2017: Revisiting the cause of the 1989-2009 Arctic surface warming using the surface energy budget: Downward infrared radiation dominates the surface fluxes. Geophys. Res. Lett., 44, 10 654-10 661, https://doi.org/10.1002/2017GL075375.

Lejenäs, H., and H. Økland, 1983: Characteristics of Northern Hemisphere blocking as determined from a long time series of observational data. Tellus, 35A, 350-362, https://doi.org/ 10.3402/tellusa.v35i5.11446.

Liu, J., J. A. Curry, H. Wang, M. Song, and R. M. Horton, 2012: Impact of declining Arctic sea ice on winter snowfall. Proc. Natl. Acad. Sci. USA, 109, 4074-4079, https://doi.org/10.1073/ pnas.1114910109.

Luo, B., D. Luo, L. Wu, L. Zhong, and I. Simmonds, 2017: Atmospheric circulation patterns which promote winter Arctic sea ice decline. Environ. Res. Lett., 12, 054017, https://doi.org/ 10.1088/1748-9326/aa69d0.

Luo, D., Y. Xiao, Y. Yao, A. Dai, I. Simmonds, and C. L. Franzke, 2016a: Impact of Ural blocking on winter warm Arctic-cold Eurasian anomalies. Part I: Blocking-induced amplification. J. Climate, 29, 3925-3947, https://doi.org/10.1175/JCLI-D-15-0611.1.

,-- Y. Diao, A. Dai, C. Franzke, and I. Simmonds, 2016b: Impact of Ural blocking on winter warm Arctic-cold Eurasian anomalies. Part II: The link to the North Atlantic Oscillation. J. Climate, 29, 3949-3971, https://doi.org/10.1175/JCLI-D-15-0612.1.

—, Y. Yao, A. Dai, I. Simmonds, and L. Zhong, 2017: Increased quasi stationarity and persistence of winter Ural blocking and Eurasian extreme cold events in response to Arctic warming. Part II: A theoretical explanation. J. Climate, 30, 3569-3587, https://doi.org/10.1175/JCLI-D-16-0262.1.

—, X. Chen, J. Overland, I. Simmonds, Y. Wu, and P. Zhang, 2019: Weakened potential vorticity barrier linked to recent winter Arctic sea ice loss and midlatitude cold extremes. J. Climate, 32, 4235-4261, https://doi.org/10.1175/JCLI-D-18-0449.1.

McCusker, K. E., J. C. Fyfe, and M. Sigmond, 2016: Twenty-five winters of unexpected Eurasian cooling unlikely due to Arctic sea-ice loss. Nat. Geosci., 9, 838-842, https://doi.org/10.1038/ ngeo2820.

Messori, G., R. Geen, and A. Czaja, 2017: On the spatial and temporal variability of atmospheric heat transport in a hierarchy of models. J. Atmos. Sci., 74, 2163-2189, https://doi.org/ 10.1175/JAS-D-16-0360.1.

— C. Woods, and R. Caballero, 2018: On the drivers of wintertime temperature extremes in the high Arctic. J. Climate, 31, 1597-1618, https://doi.org/10.1175/JCLI-D-17-0386.1.

Mondal, A., S. Kundu, and A. Mukhopadhyay, 2012: Rainfall trend analysis by Mann-Kendall test: A case study of North-Eastern part of Cuttack district, Orissa. Int. J. Geol. Earth Environ. Sci., 2 (1), 70-78.

Mori, M., M. Watanabe, H. Shiogama, J. Inoue, and M. Kimoto, 2014: Robust Arctic sea-ice influence on the frequent Eurasian cold winters in past decades. Nat. Geosci., 7, 869-873, https:// doi.org/10.1038/ngeo2277.

North, G. R., T. L. Bell, R. F. Cahalan, and F. J. Moeng, 1982: Sampling errors in the estimation of empirical orthogonal functions. Mon. Wea. Rev., 110, 699-706, https://doi.org/ 10.1175/1520-0493(1982)110<0699:SEITEO > 2.0.CO;2.

Ogawa, F., and Coauthors, 2018: Evaluating impacts of recent Arctic sea ice loss on the northern hemisphere winter climate change. Geophys. Res. Lett., 45, 3255-3263, https://doi.org/ 10.1002/2017GL076502.

Overland, J. E., K. R. Wood, and M. Wang, 2011: Warm Arctic-cold continents: Climate impacts of the newly open Arctic Sea. Polar Res., 30, 15 787, https://doi.org/10.3402/polar.v30i0.15787.

Peings, Y., 2019: Ural blocking as a driver of early-winter stratospheric warmings. Geophys. Res. Lett., 46, 5460-5468, https:// doi.org/10.1029/2019GL082097.

Perlwitz, J., M. Hoerling, and R. Dole, 2015: Arctic tropospheric warming: Causes and linkages to lower latitudes. J. Climate, 28, 2154-2167, https://doi.org/10.1175/JCLI-D-14-00095.1.

Petoukhov, V., and V. Semenov, 2010: A link between reduced Barents-Kara sea ice and cold winter extremes over northern continents. J. Geophys. Res., 115, D21111, https://doi.org/ 10.1029/2009JD013568.

Rayner, N. A., D. E. Parker, E. B. Horton, C. K. Folland, L. V. Alexander, D. P. Rowell, E. C. Kent, and A. Kaplan, 2003: Global analyses of sea surface temperature, sea ice, and night marine air temperature since the late nineteenth century. J. Geophys. Res., 108, 4407, https://doi.org/10.1029/2002JD002670.

Sato, K., J. Inoue, and M. Watanabe, 2014: Influence of the Gulf Stream on the Barents Sea ice retreat and Eurasian coldness during early winter. Environ. Res. Lett., 9, 084009, https:// doi.org/10.1088/1748-9326/9/8/084009.

Screen, J. A., and I. Simmonds, 2010: Increasing fall-winter energy loss from the Arctic Ocean and its role in Arctic temperature amplification. Geophys. Res. Lett., 37, L16707, https://doi.org/ 10.1029/2010GL044136.

_ C. Ceser, I. Simmonds, and R. Tomas, 2014: Atmospheric impacts of Arctic sea-ice loss, 1979-2009: Separating forced change from atmospheric internal variability. Climate Dyn., 43, 333-344, https://doi.org/10.1007/s00382-013-1830-9.

Serreze, M. C., A. P. Barrett, J. C. Stroeve, D. M. Kindig, and M. M. Holland, 2009: The emergence of surface-based Arctic amplification. Cryosphere, 3, 11-19, https://doi.org/10.5194/tc-311-2009.

Sigmond, M., and J. C. Fyfe, 2016: Tropical Pacific impacts on cooling North American winters. Nat. Climate Change, 6, 970 974, https://doi.org/10.1038/nclimate3069.

Simmonds, I., and P. D. Govekar, 2014: What are the physical links between Arctic sea ice loss and Eurasian winter climate. Environ. Res. Lett., 9, 101003, https://doi.org/10.1088/1748-9326/ 9/10/101003.

Sun, L., J. Perlwitz, and M. Hoerling, 2016: What caused the recent "Warm Arctic, Cold Continents" trend pattern in winter temperatures? Geophys. Res. Lett., 43, 5345-5352, https:// doi.org/10.1002/2016GL069024.

Sung, M. K., S. H. Kim, B. M. Kim, and Y. S. Choi, 2018: Interdecadal variability of the warm Arctic and cold Eurasia pattern and its North Atlantic origin. J. Climate, 31, 5793-5810, https://doi.org/10.1175/JCLI-D-17-0562.1.

Takaya, K., and H. Nakamura, 2001: A formulation of a phaseindependent wave-activity flux for stationary and migratory quasigeostrophic eddies on a zonally varying basic flow. $J$. Atmos. Sci., 58, 608-627, https://doi.org/10.1175/1520-0469(2001) 058<0608:AFOAPI $>2.0 . \mathrm{CO} ; 2$.

— and - 2005: Mechanisms of intraseasonal amplification of the cold Siberian high. J. Atmos. Sci., 62, 4423-4440, https:// doi.org/10.1175/JAS3629.1.

Tang, Q., X. Zhang, X. Yang, and J. A. Francis, 2013: Cold winter extremes in northern continents linked to Arctic sea ice loss. Environ. Res. Lett., 8, 014036, https://doi.org/10.1088/17489326/8/1/014036. 
Tibaldi, S., and F. Molteni, 1990: On the operational predictability of blocking. Tellus, 42A, 343-365, https://doi.org/10.3402/ tellusa.v42i3.11882.

Vargas Zeppetello, L. R., A. Donohoe, and D. S. Battisti, 2019: Does surface temperature respond to or determine downwelling longwave radiation? Geophys. Res. Lett., 46, 27812789, https://doi.org/10.1029/2019GL082220.

Walsh, J. E., 2014: Intensified warming of the Arctic: Causes and impacts on middle latitudes. Global Planet. Change, 117, 52 63, https://doi.org/10.1016/j.gloplacha.2014.03.003.

Woods, C., R. Caballero, and G. Svensson, 2013: Large-scale circulation associated with moisture intrusions into the Arctic during winter. Geophys. Res. Lett., 40, 4717-4721, https:// doi.org/10.1002/grl.50912.

Woollings, T., A. Hannachi, and B. Hoskins, 2010: Variability of the North Atlantic eddy-driven jet stream. Quart. J. Roy. Meteor. Soc., 136, 856-868, https://doi.org/10.1002/qj.625.

Wu, B. Y., and J. Wang, 2002: Winter Arctic Oscillation, Siberian high and East Asian winter monsoon. Geophys. Res. Lett., 29, 1897, https://doi.org/10.1029/2002GL015373.

Xu, X., S. He, F. Li, and H. Wang, 2018: Impact of northern Eurasian snow cover in autumn on the warm Arctic-cold Eurasia pattern during the following January and its linkage to stationary planetary waves. Climate Dyn., 50, 1993-2006, https:// doi.org/10.1007/s00382-017-3732-8.
Yao, Y., D. Luo, A. Dai, and I. Simmonds, 2017: Increased quasi stationarity and persistence of Ural blocking and Eurasian extreme cold events in response to Arctic warming. Part I: Insights from observational analyses. J. Climate, 30, 35493568, https://doi.org/10.1175/JCLI-D-16-0261.1.

Ye, K., T. Jung, and T. Semmler, 2018: The influences of the Arctic troposphere on the midlatitude climate variability and the recent Eurasian cooling. J. Geophys. Res., 18, $10162-10184$, https://doi.org/10.1029/2018JD028980.

Zhang, P., Y. Wu, I. R. Simpson, K. L. Smith, X. Zhang, B. De, and P. Callaghan, 2018: A stratospheric pathway linking a colder Siberia to Barents-Kara Sea sea ice loss. Sci. Adv., 4, eaat6025, https://doi.org/10.1126/sciadv.aat6025.

Zhang, X., A. Sorteberg, J. Zhang, R. Gerdes, and J. C. Comiso, 2008: Recent radical shifts of atmospheric circulations and rapid changes in Arctic climate system. Geophys. Res. Lett., 35, L22701, https://doi.org/10.1029/2008GL035607.

C. Lu, and Z. Guan, 2012: Weakened cyclones, intensified anticyclones and recent extreme cold winter weather events in Eurasia. Environ. Res. Lett., 7, 044044, https://doi.org/10.1088/ 1748-9326/7/4/044044.

Zhong, L., L. Hua, and D. Luo, 2018: Local and external moisture sources for the Arctic warming over the Barents-Kara seas. J. Climate, 31, 1963-1982, https://doi.org/10.1175/JCLI-D-170203.1. 